\title{
IDEOLOGÍAS LINGÜÍSTICAS DE LOS MALECUS CON RESPECTO A SU REPERTORIO IDIOMÁTICO ${ }^{1}$
}

\author{
Carlos Sánchez Avendaño
}

\begin{abstract}
RESUMEN
En el presente artículo, se analizan las ideologías lingüísticas de los malecus con respecto a su repertorio idiomático en el contexto del desplazamiento acusado de su lengua vernácula. En términos generales, se aprecia que las representaciones sobre las variedades lingüísticas giran en torno al eje fundamental de la identidad interétnica (los malecus en oposición a los hispanos) e intraétnica (los malecus de la comunidad de Tonjibe frente a los malecus de Margarita y El Sol). Palabras clave: malecus, ideologías lingüísticas, representaciones sociales, identidad étnica, repertorio lingüístico.
\end{abstract}

\begin{abstract}
This article analyzes the language ideologies of the Malecu people in regard to their linguistic repertoire in the context of displacement of their vernacular language. In general terms, it is noticed that their representations about linguistic varieties are founded on interethnic identity (the Malecus versus the Hispanics) and intraethnic identity (the Malecus from Tonjibe versus the Malecus from Margarita and El Sol).

Key words: Malecus, language ideologies, social representations, ethnic identity, linguistic repertoire.
\end{abstract}

\section{Introducción}

Los malecus (o guatusos) son uno de los nueve grupos amerindios asentados en el territorio de Costa Rica en la actualidad. La mayoría de la población reside en el cantón de Guatuso, provincia de Alajuela, en tres comunidades que reciben el nombre de "palenques": El Sol, Tonjibe y Margarita. Su lengua vernácula se encuentra en un avanzado estado de desplazamiento, razón por la cual la situación sociolingüística resulta ideal para el estudio de las ideologías lingüísticas que circulan en la comunidad con respecto a la naturaleza, uso y valor del idioma ancestral.

Dr. Carlos Sánchez Avendaño. Profesor de la Escuela de Filología, Lingüística y Literatura de la Universidad de Costa Rica. Investigador del Instituto de Investigaciones Lingüísticas.

Correo electrónico: tocumarama@yahoo.es

Recepción: 02- 02- 2012

Aceptación: 19- 04- 2012 
Pese a la relevancia de las ideologías lingüísticas en las investigaciones sobre el contacto, desplazamiento y muerte de idiomas, Field y Kroskriy (2009) denuncian la falta de atención que históricamente se les ha prestado en los trabajos acerca de las comunidades nativas de América, pues no se ha considerado la variedad de tales sistemas de representación social ni se ha tomado conciencia sobre la necesidad de incluir este componente en la descripción lingüística y antropológica de toda cultura. Como primer acercamiento al estudio de las ideologías lingüísticas en Costa Rica, el presente artículo constituye una descripción de algunas de las ideologías del lenguaje que circulan en el pueblo malecu en la actualidad.

\section{Las ideologías lingüísticas}

Geeraerts (2008) indica que el estudio de las ideologías lingüísticas se interesa en las creencias sobre la variación lingüística y las variedades lingüísticas específicas, y cómo estas creencias se manifiestan explícita o implícitamente e interactúan con la identidad grupal, el desarrollo económico, la movilidad social y la organización política. Asimismo, Schieffelin et al (1998b) señalan que la premisa básica en el estudio de las ideologías del lenguaje es que estas les dan forma a las prácticas lingüísticas, discursivas y sociales. Esto implica que se deben investigar las concepciones que se manejan sobre el lenguaje y la variación linguiística, la naturaleza y la finalidad de la comunicación, así como el papel de las lenguas en la vida de los grupos sociales. Tales creencias pueden "importarse" de un grupo a otro o imponerse por diversos medios, pero en todo caso son de índole múltiple y se vinculan con la experiencia social (Woolard 1998).

Además, como lo explica Woolard (1998), las ideologías lingüísticas no versan solo sobre el lenguaje, sino que muestran los vínculos de las lenguas con la identidad, la estética, la moralidad y la epistemología. Del mismo modo, constituyen la piedra angular, por medio de tales nexos, de las formas y usos lingüísticos, la definición de la persona y el grupo social, y las instituciones sociales cruciales (la socialización de los niños, las relaciones de género, las leyes, el sistema escolar, el Estado, etc.).

Fought (2006) agrega que cada grupo social cuenta con un repertorio de ideologías lingüísticas que se activan en relación con la identidad étnica, si bien estas se encuentran en constante flujo en conexión con los cambios históricos del contexto de cada comunidad, por lo que también el valor de cada código lingüístico puede variar. No obstante, parece ser común que las ideologías vinculadas con la cultura y la lengua contrapongan la asimilación al orgullo étnico, con base en la creencia de que una persona debe ser miembro del endogrupo o pertenecer al exogrupo, de manera excluyente.

Entre los diversos acercamientos al tema de las ideologías linguiísticas, el que nos interesa aquí es el que se ocupa de las creencias que rodean los procesos de contacto de lenguas en comunidades multilingües, en cuyo caso las ideologías más importantes son las relativas a las concepciones de qué cuenta como una lengua, los valores asociados con variedades lingüísticas concretas (por ejemplo, la creencia de que una lengua es mejor, más expresiva, más objetiva, más científica, etc. que otra, y también las nociones acerca de la alternancia de códigos en sujetos bilingües y, en general, todas las creencias sobre la corrección y el purismo), así como la concepción de que determinados usos lingüísticos funcionan como indicadores de identidad (Woolard 1998).

Otras aproximaciones al tema de las ideologías lingüísticas las conciben como repertorios de creencias de sentido común acerca de la naturaleza del lenguaje (Rumsey 1990), 
teorías que guían las creencias y acciones sociopolíticas grupales en relación con las escogencias lingüísticas (Heath 1989), creencias acerca del lenguaje empleadas para justificar o racionalizar la estructura y uso de las lenguas, y sistemas culturales de ideas acerca de las relaciones sociales y lingüísticas, junto con su carga de intereses morales y políticos (Woolard 1998).

Finalmente, valga destacar que, como lo indican Boudreau y Dubois (2008), dado que las ideologías del lenguaje son conjuntos de creencias compartidas por los miembros de una comunidad acerca del lenguaje y de las lenguas, suelen llegar a establecerse de modo tan firme que generalmente los hablantes olvidan su origen. En consecuencia, se reproducen socialmente y terminan considerándose naturales o propias del sentido común, con lo cual se oculta su carácter de construcción social.

\section{Datos en los que se fundamenta el presente estudio}

El discurso constituye la fuente fundamental para el estudio de las ideologías del lenguaje, pues estas, aunque suelen estar implícitas en las prácticas lingüísticas, también se muestran con explicitud en el discurso metalingüístico. Por este motivo, para el presente trabajo se recurrió a estrategias de tipo cualitativo, con el fin de recoger datos de naturaleza discursiva que nos permitieran tener acceso a algunas de las ideologías linguiísticas del pueblo malecu en la actualidad. En particular, nos decantamos por la utilización de los grupos de discusión (o grupos focales) y de las entrevistas cualitativas.

Los grupos focales constituyen una técnica de recolección de datos basada en la interacción de varias personas que se reúnen a conversar en torno a un tema (el "foco" de interés) definido por el investigador (Morgan 1997, Callejo 2001). En la discusión, se trata de que los participantes expresen sus opiniones, percepciones y conocimientos acerca del tema de conversación, en un ambiente no amenazante para ellos (Krueger y Casey 2000, Bader y Rossi 2002), por lo que resulta conveniente que se compartan ciertas características en aras de alcanzar la homogeneidad grupal en cuanto a antecedentes -no en cuanto a actitudes o ideología, claro está- (Morgan 1997, Krueger y Casey 2000). El cometido del grupo de discusión consiste en comprender la percepción del grupo acerca de una situación o fenómeno (Krueger y Casey 2000), pues se produce un discurso colectivo a partir de cada discurso individual que se comparte, escucha, contrasta, enfrenta y cruza con el discurso de los demás participantes (Russi 1998).

En lo relativo a las ventajas de esta técnica, hay que recalcar que con ella se obtiene un discurso que muestra las preocupaciones, opiniones y creencias de los individuos acerca de un tema particular, por lo que se recoge mucha más información que con las encuestas (Krueger y Casey 2000, Bader y Rossi 2002), las cuales parten de hipótesis y elementos preseleccionados que no permiten que la persona conteste más de lo que se proporciona como opción (Russi 1998). En este sentido, en una investigación en la que resulte más importante establecer las causas y el significado que le otorgan a un fenómeno las propias personas afectadas o involucradas, en lugar de realizar una descripción estadística, los grupos focales constituyen una excelente opción (Morgan 1997, Krueger y Casey 2000).

Para la configuración de los grupos, se tomaron en cuenta dos variables: la edad y el palenque de procedencia. En lo relativo a la variable etaria, cabe destacar que esta engloba diferencias diversas en cuanto a cambios en el sistema de vida de las distintas generaciones que conforman el pueblo malecu, razón por la cual la división de los grupos etarios se estableció de modo ad hoc para la presente investigación, tratando de agrupar a individuos que presumiblemente compartirían unas circunstancias de vida parecidas. 
La otra variable considerada para la conformación de los grupos fue la comunidad de procedencia, dadas las recurrentes alusiones a que la vitalidad del malecu difería entre Margarita, Tonjibe y El Sol (García y Zúñiga 1987, Constenla 1998, Mejía et al. 1995). Por este motivo, se llevó a cabo un grupo de discusión por cada generación en cada una de las tres comunidades. Además, se llevaron a cabo dos grupos de discusión familiares, con el fin de enfrentar a la generación de los padres con la generación de los hijos.

El criterio empleado en la técnica de grupos focales para determinar la cantidad de grupos que deben conformarse se conoce con el nombre de "saturación". De acuerdo con este parámetro, se alcanza un punto en el que la recolección de más datos no agrega información nueva ni genera nuevas perspectivas o interrogantes (Morgan 1997, Krueger y Casey 2000, Callejo 2001). Al mismo tiempo, la saturación temática establece la representatividad de la muestra y su fiabilidad en esta técnica (Callejo 2001). La saturación definitivamente se alcanzó en nuestro caso, pues la misma información apareció recurrentemente en los grupos de las tres comunidades y las tres generaciones. Esto nos permite suponer, asimismo, que nuestros resultados pueden "transferirse" a toda la comunidad (Krueger y Casey 2000), pues muchos de los datos se reiteran consistentemente.

Si bien los grupos de discusión constituyen la estrategia metodológica principal en el presente estudio, con los adultos mayores se estimó conveniente realizar entrevistas individuales. En total, se pudo configurar una muestra de dos personas mayores de 55 años para cada uno de los tres palenques. Además, para el palenque Margarita, fue posible entrevistar a personas mayores de 70 años. Siguiendo a Sierra (1998), el tipo de entrevista desarrollada se puede caracterizar como cualitativa. Además, en aras de mantener en la medida de lo posible la consistencia de los datos, para las entrevistas se siguió la misma agenda de sesión utilizada en los grupos focales. También se entrevistó a los maestros de lengua y cultura.

En el cuadro 1, se presenta una breve descripción de las variables del grupo o el entrevistado al que corresponde cada uno de los códigos con los que identificamos la procedencia de la información o los ejemplos:

Cuadro 1. Códigos y caracterización de cada grupo de discusión o entrevistado

\begin{tabular}{|l|l|}
\hline Código & Características del grupo o del entrevistado \\
\hline F1 & $\begin{array}{l}\text { Grupo de discusión familiar de Margarita con una amiga muy cercana de El Sol. } 7 \\
\text { participantes de los tres grupos generacionales, con edades comprendidas entre los 22 y } \\
\text { los } 61 \text { años. } 5 \text { mujeres y } 2 \text { hombres. }\end{array}$ \\
\hline F2 & $\begin{array}{l}\text { Grupo de discusión familiar de participantes procedentes de Margarita pero residentes } \\
\text { en El Sol en el momento de realizar el trabajo de campo. } 7 \text { participantes de los tres } \\
\text { grupos generacionales, con edades comprendidas entre los } 15 \text { y los } 62 \text { años. } 5 \text { mujeres y } \\
\text { 2 hombres. }\end{array}$ \\
\hline MG1a & $\begin{array}{l}\text { Grupo de discusión de jóvenes de Margarita. } 5 \text { participantes con edades comprendidas } \\
\text { entre los } 13 \text { y los } 17 \text { años. } 2 \text { hombres y } 3 \text { mujeres. }\end{array}$ \\
\hline MG1b & $\begin{array}{l}\text { Grupo de discusión de jóvenes de Margarita. } 4 \text { participantes con edades comprendidas } \\
\text { entre los } 13 \text { y los } 21 \text { años. Todos hombres. }\end{array}$ \\
\hline MG2 & $\begin{array}{l}\text { Grupo de discusión de adultos de Margarita. } 6 \text { participantes con edades comprendidas } \\
\text { entre los } 32 \text { y los } 40 \text { años. } 4 \text { mujeres y } 2 \text { hombres. }\end{array}$ \\
\hline MG3a & $\begin{array}{l}\text { Entrevista grupal a adultos mayores de Margarita. } 3 \text { participantes con edades comprendidas } \\
\text { entre los } 55 \text { y los } 74 \text { años. } 2 \text { hombres y } 1 \text { mujer. }\end{array}$ \\
\hline SG1 & $\begin{array}{l}\text { Grupo de discusión de jóvenes de El Sol. } 5 \text { participantes con edades comprendidas entre } \\
\text { los } 17 \text { y los } 30 \text { años. } 4 \text { mujeres y } 1 \text { hombre. }\end{array}$ \\
\hline SG2 & $\begin{array}{l}\text { Grupo de discusión de adultos de El Sol. } 4 \text { participantes con edades comprendidas entre } \\
\text { los } 33 \text { y los } 36 \text { años. } 3 \text { mujeres y } 1 \text { hombre. }\end{array}$ \\
\hline
\end{tabular}




\begin{tabular}{|l|l|}
\hline TN & $\begin{array}{l}\text { Grupo de discusión de niños de Tonjibe. } 6 \text { participantes con edades comprendidas entre los } \\
9 \text { y los } 13 \text { años. } 4 \text { mujeres y } 2 \text { hombres. }\end{array}$ \\
\hline TG1a & $\begin{array}{l}\text { Grupo de discusión de jóvenes de Tonjibe. } 3 \text { participantes con edades comprendidas entre } \\
\text { los } 19 \text { y los } 24 \text { años. Todas mujeres. }\end{array}$ \\
\hline TG1b & $\begin{array}{l}\text { Grupo de discusión de jóvenes de Tonjibe. } 8 \text { participantes con edades comprendidas entre } \\
\text { los } 14 \text { y los } 26 \text { años. } 5 \text { mujeres y } 3 \text { hombres. }\end{array}$ \\
\hline TG2 & $\begin{array}{l}\text { Grupo de discusión de adultos de Tonjibe. } 6 \text { participantes con edades comprendidas entre } \\
\text { los } 33 \text { y los } 46 \text { años. } 5 \text { mujeres y } 1 \text { hombre. }\end{array}$ \\
\hline MG1c & Hombre de 29 años, procedente de Margarita. \\
\hline MG3b & Hombre de 70 años, procedente de Margarita. \\
\hline SG3a & Mujer de 57 años, procedente de El Sol. \\
\hline SG3b & Mujer de 54 años, procedente de El Sol. \\
\hline TG3a & Mujer de 61 años, procedente de Tonjibe. \\
\hline TG3b & Mujer de 58 años, procedente de Tonjibe. \\
\hline M1 & Maestro, procedente de Tonjibe. \\
\hline M2 & Maestro, procedente de Margarita. \\
\hline
\end{tabular}

La muestra completa, sumando a los participantes de los grupos de discusión y las entrevistas, está compuesta por 68 personas. A este respecto, es necesario aclarar que tanto en la metodología de grupos de discusión, como en las entrevistas cualitativas, se intenta conformar una muestra selectiva o motivada. Según esto, lo más importante es que los participantes puedan generar discusiones significativas acerca del tema focal debido a que comparten una perspectiva o experiencias de vida cercanas (Morgan 1997), así que no se recurre a criterios de muestreo estadístico (aleatoriedad, representatividad) que permitan realizar generalizaciones.

No obstante, la situación demográfica tan particular del pueblo malecu permite suponer que nuestro corpus es bastante "representativo" en términos puramente numéricos: abarca el $17 \%$ de la población (si el total de esta se calcula en 400 personas) o el 13,6\% (si se establece en 500 individuos). Además, pese a que la homogeneidad estuvo presente en el reclutamiento de los participantes (con excepción de los dos grupos focales familiares), hubo suficiente variación dentro de los grupos como para que se abriera el espacio al contraste (Krueger y Casey 2000).

Los fragmentos discursivos que se consignan deben interpretarse como ejemplos de las tendencias generales que se hallan en el corpus, sea que estas tendencias estén presentes en todos los grupos, en solo los grupos determinados por cada variable o en algún grupo en particular ${ }^{2}$.

\section{Ideologías de los malecus con respecto a su repertorio lingüístico actual}

El español y el malecu son las dos lenguas genéticamente distintas que constituyen el repertorio lingüístico actual del pueblo malecu. El análisis de las etiquetas metalingüísticas (glotónimos y categorizaciones relativas al tipo de variedad lingüística) con que los participantes se refieren a ellas muestra que se conciben como dos sistemas lingüísticos separados y vinculados con distintas etnicidades, aunque ello contraste con la práctica comunicativa cotidiana, en la cual los hablantes echan mano de unos elementos lingüísticos (palabras, cláusulas, conectores, unidades pluriverbales, etc.) que genéticamente provienen del malecu simultáneamente con otros que proceden del español.

La denominación propia de la lengua vernácula es malécu lhaíca, que literalmente significa 'el habla de nuestra gente' (malécu está formado por el prefijo ma- 'primera persona 
inclusiva' y lécu 'gente, personas', y es la palabra con la que esta etnia se denomina a sí misma; por su parte, lhaíca es la forma infinitiva o nominal correspondiente a 'hablar') (Constenla 1998). Los participantes se refieren a este idioma con dicha etiqueta o simplemente con la forma 'malecu', pero también son comunes las formas 'hablar, habla, hablado malecu' o 'hablar, habla, hablado de los malecu' (F2, TG1a, TG1b, TG3a), 'nuestro idioma, nuestro dialecto, nuestra lengua' o 'mi idioma, mi dialecto, mi propia lengua' (F1, F2, MG1a, MG3a, SG3a, TG1b, TN), y con menor frecuencia 'indígena' (v.g. 'hablar (en) indígena', 'oraciones en indígena') (SG2, TG1b), sin duda debido a la traducción de malécu por 'indígena'.

En cuanto a la categorización del malécu lhaíca en el conjunto de las variedades lingüísticas, al lado de las formas 'hablar, habla, hablado' (con seguridad traducciones de la denominación en la propia lengua vernácula), se le etiqueta como 'idioma' o 'lengua' (F1, F2, MG1a, MG1b, MG2, MG3a, SG1, SG2, SG3a, SG3b, TG1b, TG2), 'lenguaje’ (SG2, SG3a, TG1b) o 'dialecto' (MG1c, MG3a, SG1, SG2, TG1b, TG2). Esta última etiqueta con probabilidad es tomada directamente de los hispanocostarricenses, quienes mayoritariamente se refieren al malécu lhaíca como "dialecto" (Sánchez Inédito), aunque al parecer no implica necesariamente entre los malecus una valoración peyorativa o la creencia de que su lengua no tenga el mismo estatus lingüístico que el español, pues usan todas las designaciones indistintamente en su discurso.

Al respecto, véase el siguiente relato de un adulto de Margarita (F2), en el cual se evidencia cómo se rechaza contundentemente el contenido evaluativo que la denominación de "dialecto indígena" tiene en la representación social de los hispanos acerca de los idiomas vernáculos de los grupos indoamericanos. Nótese cómo el hablante coloca el malecu en el mismo nivel de las otras dos lenguas más conocidas en la región (el español y el inglés) y desprecia la denominación de "dialecto" por considerar que se trata de una etiqueta impuesta, con implicaciones despectivas en cuanto a su valor:

\footnotetext{
[...] yo no hace poquito yo tuve / como un: pleito ahí porque / a mí me decían bueno / este / me dice / "ese dialecto de ustedes" / le digo "no" / entonces yo le dije que no era un dialecto que era / que que eso era / este / una lengua que nosotros teníamos / que no era dialecto / le digo "eso vinieron los españoles y dijeron que era un dialecto / pero pero pero es una lengua que nosotros tenemos como decir el inglés y / y el español".
}

La lengua introducida a partir del contacto con las personas de cultura hispana es llamada chiúti (v.g. 'hablar en chiúti') (F1, MG2, MG3a, SG2, SG3a, SG3b, TG1a, TG1b, TG3a), glotónimo que debe entenderse en realidad como una forma apocopada de chiúti lhaíca, literalmente 'el habla de los que no son malecu'. Lo más interesante a este respecto es que el término chiúti alude a cualquier persona que no sea malecu, si bien el chiúti por antonomasia en la actualidad es el hispanocostarricense (aunque también se establece la distinción entre los chiúti nacionales frente a los chiúti extranjeros); no obstante, chiúti referido al idioma solo se usa como glotónimo para la lengua española, la cual comúnmente también recibe del nombre de 'español' (F1, F2, MG1a, MG1b, MG1c, MG2, MG3a, MG3b, SG1, SG2, SG3a, SG3b, TG1a, TG1b, TG2, TG3a).

Esta dicotomía entre 'hablar malécu lhaíca (o malecu)' y 'hablar chiúti (o español)' aparece constantemente en el discurso de los participantes cuando aluden a su repertorio idiomático y a sus prácticas lingüísticas, en particular cuando tratan el tema del desplazamiento que desde hace unas décadas viene experimentando el malécu lhaíca y cuando se refieren a su escaso empleo por parte de los más jóvenes o a que estos no lo están aprendiendo. Después de que el español empezó a ser de dominio general y se incorporó de pleno en el 
repertorio lingüístico y en la comunicación intraétnica, la dicotomía entre las dos lenguas y su conceptualización como dos sistemas distintos ligados a orígenes étnicos diferentes posiblemente se ha venido enfatizando más y más, lo que con toda probabilidad tomó aún más fuerza una vez que los jóvenes empezaron a mostrar mayor competencia y uso del español que del malécu lhaíca en la conversación con miembros de la misma comunidad malecu.

\subsection{La naturaleza de la lengua malecu}

La naturaleza del malécu lhaíca se concibe con dos atributos que nos brindan una pista importante sobre las ideologías linguiísticas relativas a la lengua vernácula. Por un lado, muchas veces se alude al malécu lhaíca como el idioma propio del pueblo malecu, con lo cual se evidencia el nexo que en los modelos mentales de los individuos existe entre esta lengua y la identidad grupal de los malecus. Por otro lado, de las reflexiones y comentarios de los participantes se desprende la existencia de una concepción muy propia de este grupo: el conocimiento y la competencia de producir el arte verbal tradicional forman parte de lo que implica "saber hablar malécu lhaíca". Vamos a detenernos brevemente en estas dos cuestiones.

Dada la estrecha conexión histórica y simbólica entre la lengua malecu y la etnia malecu, evidente en la misma denominación para el idioma vernáculo (malécu lhaíca 'el habla de nuestra gente'), es común que los participantes se refieran a la lengua en términos de "nuestro idioma" (enfatizando el colectivo al que se pertenece) o "mi idioma" (proponiéndose como un individuo que se identifica con un colectivo mediante un elemento cultural propio de este). El valor identitario de esta conexión es directo en estos casos y se puede formular con la siguiente proposición ideológica: "el malécu lhaíca es el idioma de mi pueblo y también el mío propio, como malecu que soy".

Es tal la fuerza de esta representación que incluso aparece en el discurso de los participantes cuya competencia activa en el idioma autóctono es reducida. Así, por ejemplo, una joven de Margarita (F1) se refiere al malécu lhaíca como "mi idioma", pese a que precisamente lo hace para declarar que no lo habla con fluidez ("yo ya no manejo mi idioma"), en el contexto de una discusión en la que otros participantes sí han manifestado tener una competencia relativamente alta en malecu. Por lo tanto, "mi idioma" no se refiere en este caso a la lengua materna, sino a la lengua vernácula del pueblo al que se adscribe el individuo.

Debido a la existencia de esta asociación entre el idioma autóctono y la etnicidad malecu en la representación ideológica de los participantes, en su discurso estos informan de diversos comportamientos idiomáticos que son interpretados como "actos de identidad", en el sentido con el que Le Page y Tabouret-Keller (1985) emplean este constructo: como formas de conducta que reflejan la afiliación y las actitudes de un individuo hacia un grupo. Así, las prácticas lingüísticas individuales de los malecus son valoradas por los participantes como formas de expresión de actitudes hacia su origen étnico, su lealtad hacia el grupo y su adhesión a la tradición cultural del pueblo. Tales conductas individuales se generalizan a todo un colectivo.

A este respecto, por ejemplo, responder un saludo en malécu lhaíca se interpreta como una prueba de que el sujeto se identifica con su pueblo y no se avergüenza de su ascendencia. Por el contrario, los participantes censuran que los jóvenes de Margarita respondan en español cuando se les saluda en malecu, ya que parten del supuesto de que el malecu es la lengua propia de la etnia y de que todo malecu debería hacer el esfuerzo de por lo menos intentar contestar en la lengua vernácula, de modo que se considera que tales jóvenes 
están demostrando con sus respuestas una actitud de rechazo o desarraigo con respecto a la cultura de sus ancestros.

Por lo demás, surge también en el discurso de los participantes una conexión mucho más compleja, si bien ligada con el valor identitario de la lengua vernácula. Se trata de una creencia acerca de la capacidad de aprender y hablar malecu, que de alguna manera parte de que esta ha de ser innata en los descendientes de malecus por el solo hecho de "traerse en la sangre".

La asociación entre identidad étnica malecu, ascendencia ("sangre") y pureza es un rasgo característico de las representaciones sociocognitivas de los malecus acerca de su etnicidad (Sánchez 2011), de modo que no es de extrañar que exista la creencia (consciente o no) de que si la etnicidad se hereda genéticamente ("soy malecu porque llevo sangre malecu"), también la lengua, componente importante de dicha identidad, debe de heredarse, al menos como potencialidad ${ }^{3}$. Esta creencia se manifiesta, de una u otra forma, en el discurso de algunos de los participantes de los tres palenques y de diversas edades (F2, MG1c, MG2, MG3a, SG3b, TG1b), lo que indica que probablemente forma parte del sistema de representación social compartido por muchos miembros de la etnia.

Esta concepción del carácter innato de la capacidad para hablar malécu lhaíca por llevar sangre malecu aparece incluso con más fuerza y claridad cuando los participantes reflexionan sobre la pérdida de la lengua vernácula y la escasa competencia en esta que muestran las nuevas generaciones, en gran medida como consecuencia del mestizaje, el principal motivo del desplazamiento de la lengua autóctona en la representación ideológica de los participantes (Sánchez 2011). En este caso en particular, el nexo entre ascendencia étnica y propensión a hablar un idioma determinado también se concibe para el español.

Por ejemplo, en el siguiente fragmento, un participante de Margarita (F2) achaca al mestizaje una especie de lucha entre los dos idiomas por llegar a manifestarse. En su discurso, el participante se refiere al inicio del desplazamiento (la "pérdida") de la lengua vernácula ubicándolo en el tiempo de los primeros contactos prolongados con el grupo de cultura hispánica (los huleros nicaragüenses):

[...] yo creo que nosotros empezamos a perder / el malécu lhaíca nos podemos remontar un poco más / al tiempo de que se hicieron las mezcla de de nicaragüenses con con con indígenas / cuando el tiempo de la hulera y eso entonces ya empezaron / ahí fue donde tuvimos el cruce / este / de donde se cruzaron muchas personas y después de ahí / este digamos / ya empezó ese cruce / entonces / como la la sangre mía / tiende a a hablar el malecu pero la la otra contraparte también el español / entonces este / ahí es donde venimos luchando contra eso [...]

La misma representación ideológica se encuentra en el modelo mental expresado en el discurso de una mujer de El Sol (SG3b), quien explica que sus hijos no adquirieron bien el malecu ("no lo agarraron bien", en los términos en los que los malecus suelen referirse a la adquisición de una lengua) porque el padre de ellos era chiúti, de forma tal que el mestizaje ha interferido en que sus descendientes desarrollen competencia activa en la lengua vernácula:

I: ¿y cuando ellos eran chiquitillos sí hablaban malecu?

A: $\quad$ yo desde pequeñito le enseñaban ¿verdad? / pero me agarraron más el español / yo digo que por el cruce seguro ¿verdad? / con chiúti / como usted / chiúti \{risas\}

I: ajá ajá ajá / pero pero / ¿y y y qué es? / ¿que: que los chiútis les hablaban a ellos solo en español y por eso entonces ellos?

A: $\quad$ no / es que son como ya son cruzados con gente blanco ellos ya / donde sí se puede agarrar ellos es creo cuando si al- alguien / si por ejemplo / si yo me me / estoy juntada con misma persona ¿verdad? / malecu / yo digo que así pueden hablar bien ¿verdad? [...] 
Nótese cómo la mujer desestima la suposición del entrevistador de que el problema de la falta de competencia de los niños en la lengua vernácula surgió porque el padre no malecu y otros hispanos les hablaban en español a sus hijos. La participante reitera, por el contrario, que el mestizaje étnico-genético ("cruce") es el responsable, pues si se tratara de malecus "puros" hablarían mejor el idioma autóctono.

La misma ideología de la lucha o incompatibilidad entre los dos idiomas subyace a otras creencias y da cuenta de ciertos comportamientos lingüísticos actuales. Por ejemplo, los participantes informan de algunos intentos aislados en Tonjibe de transmitirles la lengua vernácula a los más pequeños de la familia. En particular, en nuestros datos aparecen alusiones a niños pequeños que han sido criados en un ambiente con predominio del malecu en la interacción cotidiana del hogar por una decisión consciente de los adultos, con la justificación de que escuchar o aprender español puede interferir y hasta frenar la adquisición y uso del malecu (SG3a, TG1b, TG3a), como lo relata la siguiente joven de Tonjibe (TG1b):

Sí en el caso de mi casa / mi papá no nos deja que le hablemos español a la chiquita / él nos exige a nosotros ahí hablar el idioma de nosotros / pero: / nosotros lo hablamos cuando está la chiquita pero: cuando la chiquita se quita / entonces nosotros empezamos a hablar en español / porque él dice que si la chiquita empieza a captar unos: / las palabras / se le puede olvidar el malecu.

El otro componente "peculiar", que en el pensamiento de este pueblo parece estar incluido en lo que se entiende por hablar malecu es el arte verbal, esto es, las manifestaciones del lenguaje cuya finalidad no corresponde a la función referencial o a un propósito meramente comunicativo cotidiano, sino que representan formas elaboradas del lenguaje empleadas para transmitir el conocimiento ancestral de la etnia, para desencadenar el poder de fuerzas sobrenaturales y para entretenerse en grupo.

Sin entrar en detalle en la riquísima gama de modalidades discursivas de este tipo propias de la cultura tradicional malecu, hemos de mencionar que algunas de las manifestaciones del arte verbal son los mayupéca (lit. 'el decir obscenidades') 'duelo verbal', tócu ajá malhaíca (lit. 'el hablarle a un Dios') 'plegarias', póra 'fórmula mágica curativa o de hechicería', majuáqui urújecá (lit. 'el calentar un rostro') 'fórmula de petición de protección a los Dioses frente a los malos espíritus', porétecá (lit. 'el cantar') 'canción personal de tema amoroso', los macuápeca (lit. 'deseo de que alguien muera') 'maldiciones' y los marácunúca (lit. 'el escucharse') 'pláticas tradicionales' (sobre los Dioses, la transformación de la tierra, los matrimonios con animales, la relación con ciertos seres sobrenaturales, etc.) (Constenla et al. 1993). Implícita o explícitamente, con frecuencia aparece la creencia de que alguien que habla bien malécu lhaíca debe conocer y ser capaz de producir estas manifestaciones de arte verbal (F1, F2, MG2, MG3a, TG1b, TG2, TN, M1).

Debido a esta asociación entre el sistema lingüístico y el arte verbal como parte de lo que se considera hablar el idioma autóctono, es frecuente que los participantes se autocalifiquen espontáneamente en una escala de uno a cien en cuanto a su competencia lingüística en malécu lhaíca y que, cuando no se asignan el porcentaje completo, ello se deba a que desconocen manifestaciones específicas del arte verbal, como se observa con claridad en la siguiente respuesta de un joven de Margarita (F1), quien, por lo que pudimos notar en nuestras observaciones, podría calificarse de bilingüe equilibrado:

I: A / usted dice que usted piensa que lo habla en un cincuenta por ciento / ¿qué qué es lo que te falta? / ¿cuál es el cincuenta por ciento que no sabés?

A: $\quad$ es que yo digo eso / ¿por qué? / porque yo no sé las oraciones que hace / B / eh hay una oración que se llama lhaláqui ipcuápeca maráma [[maldición de la serpiente]] / que es como / cuando alguien discute con alguien / y un ejemplo / hacerle una oración / una maldición / eso yo no 
lo sé / hay algunas oraciones / es / digamos / para / para este / para / fortalecer a los niños \{se refiere a los majuáqui urújecá 'fórmulas de robustecimiento espiritual'\} / qué sé yo / unas oraciones ahí / yo no lo sé / ¿ves?

En suma, debemos entender que la concepción de lo que constituye el malécu lhaíca para la comunidad incluye tanto los recursos idiomáticos (palabras, oraciones, sonidos, fórmulas de salutación, etc.) como las manifestaciones discursivas exclusivas de la cultura tradicional de la etnia y que, claro está, se expresan normalmente por medio del código lingüístico autóctono. Además, al concebirse el malécu lhaíca como la lengua propia del pueblo malecu, aparece con recurrencia un nexo entre este y el criterio de ascendencia étnica en términos cuasi-genéticos: ser malecu es algo que "se trae en la sangre" y, si la lengua malecu es la propia y exclusiva de los malecus, entonces para muchos participantes resulta natural considerar que de alguna manera existe una propensión genética a hablar ese idioma y que ello también se lleva en la sangre.

Además del vínculo anterior, la ideología de la pureza y la autenticidad, muy común en las representaciones sociales de los malecus (Sánchez 2011), conlleva a se conciba que el idioma malecu original es el que se hablaba antes y, en el presente, el que hablan únicamente los ancianos, en vista de que los adultos y jóvenes desconocen ciertas palabras y ello no es más que un signo de que la cultura y el idioma ancestrales están desapareciendo (F2, MG2).

La siguiente intervención de un adulto de Margarita (MG2) muestra cómo se manifiesta esta ideología. En el fragmento, se puede observar con claridad cómo se piensa que la pérdida de determinados vocablos, generación tras generación, es un indicio de que el idioma ancestral está en decadencia y de que el caudal léxico va a ir decreciendo conforme pasen los años. Nótese cómo el participante establece dos categorías: las palabras "más originarias" (las ya extintas o que los de su generación desconocen) y las que se emplean en el presente:

\footnotetext{
[...] aquí yo hablo con mi mamá / yo hablo con esa señora y yo soy sincero / no me avergüenzo / ella me me me dice algunas palabras / y yo tengo que preguntarle "mami / ¿eso qué significa?" / un día de estos yo: estaba / eh: / estaba hablando y y y ella me dice este: / ¿nocófa curíjurí tiní miri lharránye?" [[¿andás pulseando a varias mujeres?]] / yo tuve que ir / "mami / ¿eso qué significa?" / y eso que yo digo que yo sé hablar el ochenta por ciento de malecu / y y y / y de eso que el malecu originario se está perdiendo porque / yo una vez hablaba con A / el el el malecu en ú purújaco [[aldea]] / que era una comunidad grande en / sobre la la la la cuenca del río este: / [...] / La Muerte / ahorita usted va y en la finca de nosotros usted encuentra / huesos de de / de personas / [...] / este / huesos humanos / no le estoy mintiendo ahí / este: / chíu / que es este ba- / olla de barro quebrado ahí sobre la orilla del río / ellos / decían este / púrinharanhca / púrinharanhca / y nosotros decimos túfi / y púrinharanhca ya eso este / esa palabra ya / se extinguió / es una palabra más más originaria / nosotros decimos túfi / que es el pavón / entonces este este: / hay palabras que que ya se extinguió / o que esa gente sí lo hablaba / entonces si yo digo que yo hablo el ochenta por ciento / yay imagínese aquí dentro de treinta años / por más / como le digo / por más que yo quiera hablar malecu hay muchas palabras que mi mamá habla conmigo aquí / y y desgraciadamente yo no lo sé / yo tengo que preguntar [...]
}

Con la dicotomía relativa a la vitalidad del léxico se alude a una dicotomía más amplia: la de lo original frente a lo menos original (y, como consecuencia, lo menos puro y menos malecu) y, por extensión, la de los malecus legítimos (los que hablan el malecu original, incluyendo a los ancianos de ahora) frente a la de los malecus menos legítimos. Apréciese cómo el hablante considera que su dominio más reducido del idioma autóctono es prueba de que, de la generación de los ancianos a la suya, ya se ha perdido parte del léxico del "malecu originario".

Por lo demás, se revela con claridad la concepción de que el malécu lhaíca quedó fijado en el pasado y que lo único que puede suceder desde entonces es la pérdida de su estado 
original. Esta cognición subyace al rechazo contundente de la creación de nuevas palabras, una actitud generalizada en el discurso de los participantes (F1, MGla, MGlb, MG2, SG1, SG2, SG3a, TG1a, TG1b, TG2), lo que sin duda alguna se debe la consideración de que no se puede modificar la forma original y legítima del idioma ancestral. Como justificación, los participantes alegan que la lengua vernácula carece de ciertos vocablos debido a que los malecus antiguos no conocían los objetos a los que estos se refieren (F1, F2, MG2, MG3a, SG1, SG2, SG3a, TG1a, TG1b, TG2) y que, por lo tanto, no es correcto "inventar". En el relato de la siguiente adulta mayor de El Sol (SG3a) se contrapone "lo inventado" a "lo original" (lo que ya existía en el tiempo de sus ancestros):

\begin{abstract}
[...] una vez me dijeron “¿cómo se dice este: / 'carro'?” / le digo "yo te puedo decir pero invento" / yo / me dice / "diay / de por sí el lenguaje malecu es invento" / "no" le digo / "no creo / todo no son invento" / le dije / porque: / el carro / me dice "ipor qué?" / "porque no hay carro" le digo / "porque diay en aquel entonces cuando fueron mis bisabuelos / mis tatarabuelos no habían carros / no había nombre 'carro"'.
\end{abstract}

\title{
3.2. $\quad$ La variación del malécu lhaíca
}

Si bien en la actualidad los mismos malecus aluden a diferencias de tipo geolectal dentro de su lengua, explican que ellas se remontan a variedades ligadas a los lhija maráma, agrupaciones en que parecía estar dividida la etnia en el pasado y que Constenla $(1975,1998)$ traduce como 'linajes', aunque entre los malecus a veces se escucha el término 'clan', el cual no debe entenderse en la acepción con que se maneja técnicamente este vocablo en antropología ${ }^{4}$. Es decir, la variación del malécu lhaíca parece haber sido en un inicio una variación que dependía de grupos familiares, del linaje al que pertenecía el individuo, por lo que no se trataba de geolectos en sentido estricto.

$\mathrm{Al}$ respecto, Constenla (1998) asegura que las diferencias entre los hablantes de una misma comunidad podrían deberse a diferencias en la forma de hablar de los distintos linajes familiares que antiguamente componían la sociedad malecu, en vista de que, al reasentarse en otras localidades tras la persecución por parte de los huleros en el siglo XIX, posiblemente confluyeron varios de estos grupos en la nueva comunidad de Margarita (Constenla 1975). Un ejemplo de tal variación sería la alomorfia del tema verbal chúji chúfi 'dormir' y la del sufijo de modo real -nhe -ye en combinación con este mismo tema verbal, de manera que se presentan formas alternantes como chúfiye y chújinhe en Margarita (Constenla, comunicación personal).

En la actualidad, parece ser que muchos participantes conciben que a cada uno de los tres palenques corresponde originalmente un linaje, lo que explica la variación diatópica del malécu lhaíca en el pasado y la que aún persiste en el presente (F1, MG2, TG1a), como queda claro en lo que afirman los siguientes dos ancianos (F1):

B: $\quad$ es como por ejemplo aquí en El Sol / yo recuerdo / pero te estoy hablando / de las personas / tal vez yo no sé si él recuerda / unos viejitos que ya no existen / yo le / yo le escuchaba decir "pá natonh"/ “¿múri mitonh?” [[“ya vine” / “ide dónde viene?”] / nosotros \{se refiere a los de Margarita\} decimos ¿mírre mitonh? [[¿de dónde viene?]]

A: $\quad$ mírre mitonh

B: $\quad$ pero es el hablado de ellos

A: $\quad$ sí / perdoná B / es lo que yo le decía / el clan

B: ajá

A: el clan / porque mi papá también decía / mi papá no decía mírre sino múri

B: ujú 
A: ese es el clan ¿verdad? / por eso yo le decí- / le decía ahora / el clan / e- e- eso / el clan / un clan es de Tonjibe / otro aquí \{se refiere a El Sol\} / y el otro en Margarita.

Los participantes reconocen la existencia de dicha variación en el nivel fonológico, el discursivo y el léxico, de entre los cuales el primero es el más ampliamente citado.

\subsubsection{Variación fonológica}

Con respecto a la variación fonológica, los participantes mencionan diferencias en la pronunciación sin especificar más detalle (MG1a) o aluden al "acento" (en abstracto o referido en realidad a diferencias en cuanto a ciertas curvas de entonación en el malecu de Tonjibe frente al malecu de Margarita y El Sol) (SG2, SG3b), pero el fenómeno más sobresaliente en el discurso de los participantes es el que hemos de denominar aquí el geísmo ${ }^{5}$, consistente en la fusión de los fonemas $/ \mathrm{y} / \ll \mathrm{lh} » \mathrm{y} / \mathrm{x} /\langle\mathrm{j} »$ a favor de $/ \mathrm{x} / 6$.

En relación con este fenómeno, en sus datos de principios de los 70, Constenla (1975) informaba que algunas hablantes conservaban la distinción con una realización [1] de /4/ en todas las posiciones o con una alternancia [ $\mathrm{k} \sim \mathrm{s}]$ (como fricativa ápico-alveolar al inicio de morfema y como lateral en los demás entornos); otros hablantes no presentaban /4/ en posición inicial de morfema, sino solo en posición interna y presentaban / $\mathrm{x} /$ en lugar de /4/ en los morfemas en los cuales los hablantes del primer grupo mencionado tenían /4/ inicial; y un tercer grupo presentaba /x/ en todas las posiciones y carecía, por tanto, de /4/ dentro de su inventario fonológico. De esta manera, se daban las formas [ła:ka ssa:ka] 'cucaracha' y [ku:ła] 'ardilla' en el primer grupo, [xa:ka] y [ku:ła] en el segundo, y [xa:ka] y [ku:xa] en el tercero.

Hace unos cuarenta años, la fusión total (la tercera solución fonológica) parecía ser característica de Tonjibe, mientras que la primera solución (la conservación total y la alternancia) se hallaba en los tres poblados y era la única presente en El Sol. Por su parte, la segunda solución (conservación de / / solo en posición interna) únicamente estaba presente en Margarita y parecía estarse imponiendo entre los jóvenes. De acuerdo con Constenla, el geísmo se habría comenzado a producir en la transición del siglo XIX al XX y dio como resultado, para la década de 1970, la completa desaparición de /4/ en Tonjibe. Esto es, el geísmo parece ser más un cambio en marcha desde finales del XIX (Constenla 1975) que una variación relacionada con los linajes, aunque en la actualidad varios participantes adjudiquen su origen a la antigua división de la etnia (F1, TG1a).

En el presente, el geísmo es considerado por los participantes de distintas edades y de los tres palenques como un rasgo lingüístico que claramente distingue y opone el malecu hablado en Tonjibe al malecu hablado en Margarita y El Sol (F1, MG1c, MG2, SG1, SG2, SG3b, TG1a, TG2, M2). Incluso es común que los participantes de los distintos grupos y entrevistas proporcionen en su discurso los mismos ejemplos léxicos. Así, los pares múlhu [mu:łu] / múju [mu:xu] 'pescado' y cúlha [ku:ła] / cúja [ku:xa] 'ardilla' resultan los ejemplos por excelencia. En el siguiente fragmento, una participante de El Sol (SG3b) alude a tales diferencias con claridad ${ }^{7}$ :

[...] la gente de Tonjibe / la gente de Tonjibe / hablan [...] / hablan / la gente de Tonjibe ha- / te ha- te dicen unas cosas que a veces nosotros \{se refiere a los de El Sol\} / nosotros a veces los estudiamos aquí / nosotros / por ejemplo / ellos dicen mafíji / nafíjióra [[el ojo, mi ojito]] / y nosotros le decimos aquí nafílhi [[mi ojo]] / ellos dicen mafíji es 'los ojos'8 / y nosotros le decimos aquí nafílhi [[mi ojo]] / ¿ves? / y para decir 'pescado' ellos / de Tonjibe / en malecu dicen múju / y nosotros aquí hablamos múlhu / ¿ve qué diferente? 
Lo mismo ocurre cuando los tonjibeños se refieren a las diferencias de su variedad de malecu con respecto al de Margarita, como se aprecia en las siguientes intervenciones de dos jóvenes (TG1a):
A:
[...] allá \{se refiere a Margarita\} tienen un hablado diferente que aquí \{se refiere a Tonjibe\} / por ejemplo nosotros aquí: decimos cúja / cúja ¿verdad? / que es la ardilla / y ellos dicen allá cúlha \{risas\}
B:
y aquí nosotros decimos / al pescado múju / y allá múlhu \{risas\}.

A este respecto, las representaciones ideológicas encontradas en nuestros datos ilustran el proceso semiótico denominado "borrado" por Irvine y Gal:

\begin{abstract}
Erasure is the process in which ideology, in simplifying the sociolinguistic field, renders some persons or activities (or sociolinguistic phenomena) invisible. Facts that are inconsistent with the ideological scheme either go unnoticed or get explained away. So, for example, a social group or a language may be imagined as homogeneus, its internal variation disregarded. Because a linguistic ideology is a totalizing vision, elements that do not fit its interpretative structure -that cannot be seen to fit- must be either ignored or transformed. (2009: 251)
\end{abstract}

En la representación social acerca de la diferencia sociolingüística entre las comunidades, tal y como se manifiesta en el discurso de los participantes, el proceso de "borrado" aparece en este caso para asegurar la existencia de dos patrones de pronunciación opuestos, fijos y característicos de cada uno de los palenques: "los de Tonjibe pronuncian $[\mathrm{x}]$ mientras que los de los otros dos palenques pronuncian [1]"; aunque ello contraría la realidad actual: en Margarita y El Sol también se produce la fusión, pues, como ya se señaló, el geísmo es un cambio en marcha que afecta a las tres comunidades y la única diferencia radica en que el cambio está completamente consumado en Tonjibe. No obstante, es tal la seguridad con la que los participantes de Margarita y El Sol creen que el geísmo es propio de Tonjibe que simplemente no parecen ser conscientes de que también ellos lo presentan, o son conscientes pero establecen una frontera geolectal entre ellos y los tonjibeños que los lleva a hacer caso omiso de la realidad.

Es común que el geísmo, así como la variación en los demás niveles, no reciba una valoración purista por parte de los participantes. Por el contrario, se suele aseverar que se trata de una simple diferencia en la forma de hablar y que es el mismo idioma, de manera que no suelen surgir problemas de comprensión entre las personas de distintos palenques (F1, F2, MG1a, MG1c, MG2, M2), si bien no están ausentes por completo actitudes de rechazo ni las opiniones que destacan la superioridad de las variedades que conservan [1] frente a la totalmente geísta de Tonjibe, como se puede apreciar en la siguiente discusión en la que participan tres adultos de El Sol (SG2) y en la que se pondera la dificultad articulatoria de [1] frente a [x]:

$\begin{array}{ll}\text { B: } & \text { el / el colibrí / este / se llama / bueno / nosotros } \\ & \text { pilhío / y ellos }\{\text { se refiere a los de Tonjibe }\} \text { le dicen } \\ \text { A: } & \text { ¿cómo lo pronuncia usted? / yo antes lo escuché } \\ \text { I: } & \text { yo dije pílhi } \\ \text { A: } & \text { ajá / ¿ves? / es que } \\ \text { C: } & \text { así así } \\ \text { A: } & \text { así hablamos nosotros } \\ \text { C: } & \text { yo pienso que hablamos mejor nosotros } \\ \text { I: } & \text { ¿sí? } \\ \text { D: } & \text { no / pero pero digamos } \\ \text { C: } & \text { o sea / como }\end{array}$




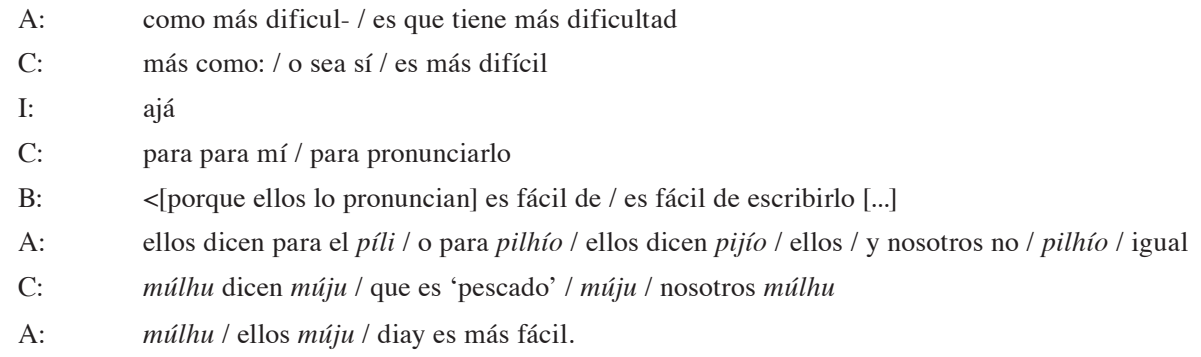

La oposición entre Tonjibe, por un lado, y Margarita y El Sol, por otro, es una constante en las representaciones ideológicas del pueblo malecu en el presente, lo que en el discurso suele manifestarse mediante la dicotomía deíctica de "nosotros" frente a "ellos" (o "aquí" frente a "allá"), como se puede apreciar en todos los ejemplos analizados. En este sentido, el geísmo actúa como una marca de diferenciación lingüística que evidencia, en términos de lenguaje, la oposición que de todas formas -según se piensa- abarca muchos otros componentes culturales, físicos y actitudinales, relacionados con la ideología de la autenticidad y con el desplazamiento de la lengua vernácula (Sánchez 2011).

\title{
3.2.2. Variación discursiva
}

La variación discursiva se reconoce en relación con el arte verbal (F1, MG2, TG1b), pues parece que las narraciones y otras manifestaciones discursivas presentan diferencias atribuibles también a los linajes. En este aspecto en particular, según los participantes, la variación lingüística provoca con mayor realce frecuentes disputas entre los miembros de los distintos palenques, dado que las publicaciones del arte verbal que se han realizado hasta la fecha y que se emplean en las escuelas recogen muestras discursivas de determinados sujetos con la versión de su propio linaje. El siguiente adulto de Margarita (MG2) se refiere a este tema:

\begin{abstract}
Ajá / y y resulta que / que el malecu / en malecu hay varios clanes / y y a según / a según papá / el clan de nosotros / de la familia nuestra es este: / corócu lhíja / y y y el corócu lhíja al lhafánhji jija / hay / hay un este / ¿cómo se llama? / ¿cómo le digo? / hay un este / una pronunciación de de algunos / de algunas enseñanzas diferentes como por ejemplo / el este / el corócu lhíja dice / nínique ní tocpúru tácufa milha najuáqui arra ururuquiné ururuquiné cánho táque [[este árbol ardiente que me pegue el ardor de este fuego hacia mi cara]] / pero dice que el el el lhafánhji lhíja dice / nínique ní ni ni tocpúru / milha najuáqu arra ururuquiné ururuquiné táque nada más / cánho / dice el clan de nosotros / y el otro clan dice táque nada más / entonces cuando / cuando yo veo ese libro elaborado por A y por B / yo veo que está bien / porque así fuimos enseñados nosotros / entonces cuando lo ve otro clan de otro / [...] / ellos dicen que / que está mal.
\end{abstract}

\section{El malecu y el español en competencia o en convivencia en la actualidad}

Se podría proponer que el repertorio lingüístico de los malecus aumentó cuando se generalizó su conocimiento del español alrededor de la segunda mitad del siglo XX, para luego dar paso a una reducción paulatina que ha desembocado en el desplazamiento cada vez más acusado del malécu lhaíca desde finales de la década de 1970. Es decir, es posible que durante algunos años haya existido un bilingüismo social estable con una especialización funcional de las dos lenguas, circunstancia en la cual el malecu se empleaba en la comunicación intraétnica en todos los dominios funcionales tradicionales, mientras el español se utilizaba en la comunicación interétnica (para negociar o tratar de asuntos diversos con los chiúti, 
para conversar con los visitantes foráneos). Sin embargo, tal situación no perduró, sino que el bilingüismo se volvió sustractivo una vez que las nuevas generaciones empezaron a adquirir el español "a expensas" del malécu lhaíca.

En el caso de las personas con un bilingüismo activo (equilibrado o subordinado, simultáneo o sucesivo), sin duda el malecu y el español conviven actualmente en su cotidianeidad. Por su parte, los bilingües receptivos, los semilingües y los monolingües en español viven la presencia cotidiana del malecu, pero sus posibilidades de formar parte activa de las interacciones llevadas a cabo en la lengua vernácula o en la modalidad bilingüe son mínimas o nulas. En todos los casos, la conceptualización de la situación sociolingüística actual es que el malécu lhaíca se está perdiendo y que ello tiene implicaciones para la construcción de la identidad étnica malecu. Empero, la creencia de que ambas lenguas deberían coexistir (el mantenimiento del bilingüismo activo) parece predominar y defenderse, en vista de que cada uno de los idiomas involucrados cumple funciones específicas dentro del repertorio.

A este respecto, una constante en el discurso de los participantes de los tres palenques y de todos los grupos generacionales fue la declaración expresa o la creencia implícita de que el bilingüismo malecu-español es lo deseable en la actualidad (F1, MG1a, MG1c, SG2, SG3a, TG1b, TG2, TG3b). Esto se debe a que los participantes conciben como una ventaja que su repertorio lingüístico esté compuesto por dos lenguas, puesto que ello les permite comunicarse en español con los chiúti de la región y otras partes del país (así como también tener acceso a la educación formal), y poder recurrir al malécu lhaíca en la comunicación con otros malecus, como código críptico y con funciones identitarias.

A modo de ilustración, en un peculiar engarce entre estas funciones, el siguiente joven de Margarita (MG1a) plantea una especie de diglosia determinada por la etnicidad del interlocutor. Por lo demás, nótese cómo, aun teniendo una competencia muy reducida en malecu y siendo el español su lengua materna, el joven establece una dicotomía entre "mi idioma" (como malecu que es) y "su idioma" (el de los "blancos"), de forma tal que se refuerza el valor etnoidentitario de la lengua vernácula:

\footnotetext{
En una ocasión yo le dije a mi mamá que: / si ella / no me hubiera / no me hubiera enseñado más español que malecu / yo le dije / yo sería ahorita una / otra persona / porque digamos un ejemplo / a los malecus / yo le hablaría en mi idioma y a los blancos en su idioma.
}

Resulta reveladora la consideración del joven de que el bilingüismo equilibrado lo habría convertido en "otra persona", es decir, concibe su identidad personal en gran medida como dependiente de su repertorio lingüístico y, además, como construida a partir de su pertenencia al colectivo ("mi idioma" se refiere al idioma de la etnia de la que forma parte). A este respecto, según su concepción, la competencia activa en ambas lenguas le permitiría participar en el mundo de los malecus y en el mundo de los "blancos" con el código lingüístico asociado a cada uno de ellos.

Algunos participantes rechazan explícitamente el monolingüismo en malecu (MGlc, SG2, TG2) por conllevar problemas de adaptación a la educación formal, debido a que se aduce que en el colegio los profesores imparten la materia en español o se afirma que los niños podrían tener problemas en la escuela y que es su derecho ser bilingües para ser capaces de interactuar con los hispanohablantes. El mejor ejemplo de posicionamiento al respecto se encuentra en el grupo de los adultos de Tonjibe (TG2), cuando surgió en la discusión el caso de una niña a quien su familia ha procurado proveerle un estímulo lingüístico solo en 
malecu y cuya competencia en español parece ser sumamente limitada. La mujer que trae a colación el caso alega que la niña está aislada y que no puede comunicarse en español cuando así lo requiere. Para reforzar su tesis echa mano del relato de dos experiencias que ilustran la inconveniencia del monolingüismo en malecu en el presente: una experiencia en una tienda de alimentos ("pulpería") y otra en la escuela:

I: $\quad[\ldots]$ ¿y qué opina la gente aquí en Tonjibe de que esa chiquita no hable español?

A: en parte / en parte / es importante / a mí / bueno el caso mío / es muy importante pero una parte / una parte no / que le hable todo en / malecu / porque en parte que: / porque una vez fui yo a la pulpería / la: señora que estaba atendiendo la pulpería le entendió / porque / dijo "leche"10 / por eso es que le entendió / dijo este / ¿qué era? / "picarita"/ pero todo le dijo "por favor / necesito que me dé una leche" pero todo en malecu / y la: señora la atendió / ¿por qué? / porque dijo "leche" / dice "ah sí / ¿usted quiere una leche?" / y ella le dijo "sí sí" / pero / ahí es / donde está la pega de esa niña / ¿por qué? / porque le va a costar mucho entender a los demás / llegará el momento que usted / ella le va a hablar todo en malecu / usted no va a saber qué le está hablando / y si te / si usted le dice / si usted le dice "yay ¿pero qué me estás diciendo?" / me dijo / me dijo / un día de estos / le digo yo "¿usted va en el kínder?" / me dice "sí" / pero le hablé todo en malecu / le digo "y ¿qué? / ¿usted entiende algo hablando (XX)?" / me dice "es que ellos no me entienden a mí" / todo en malecu me dijo "es ellos / a mí no me entienden" me dice / "entonces yo no puedo conversar con ellos" me dice / le digo "¿pero ellos quieren jugar con usted?" / me dice "sín" me dice / "pero es que / yo no puedo" me dice / "porque yo no sé entender" / dijo / y en parte / en parte este / ¿cómo le dijera? / sí / no me gustaría a mí así / ¿por qué? / porque a mí me gustaría que ambos dos / interprete las dos cosas.

Lo más importante de notar aquí, es que el problema nunca se plantea en términos de por qué los otros niños no hablan malecu o por qué la vendedora es incapaz de comprender este idioma pese a que su negocio está dentro del territorio indígena. Concebir que el problema es del monolingüe en malecu y no del monolingüe en español revela, a fin de cuentas, el desequilibrio de poder entre los grupos y la concomitante diferencia en el estatus de las lenguas, lo cual se asume y se expresa implícitamente en el discurso como "lo normal" o "lo esperable". En este sentido, ciertamente estamos ante un ejemplo de dominación simbólica:

\footnotetext{
Cualquier dominación simbólica implica, por parte de los que la sufren, una especie de complicidad que no es sumisión pasiva a una norma externa ni adhesión libre a valores. El reconocimiento de la legitimidad de la lengua oficial no tiene nada que ver con una creencia profesada expresamente, deliberada y revocable, ni con un acto de intenciones de aceptación de una «norma»; se inscribe, en la práctica, en las disposiciones que se inculcan poco a poco, a través de un proceso de adquisición largo y lento, mediante las sanciones del mercado lingüístico y que se encuentran de este modo ajustadas, fuera de cualquier cálculo cínico y de cualquier imposición conscientemente sentida, a las posibilidades de beneficio material y simbólico que las leyes de formación de los precios, características de un mercado determinado, prometen objetivamente a los propietarios de un determinado capital lingüístico. (Bourdieu 2008: 29-30)
}

Pese a la representación que da cuenta de la desigualdad de estatus social entre el malecu y el español, no faltan los casos de participantes que defiendan expresamente que el idioma vernáculo sea la primera lengua en ser adquirida, antes que el español o cualquier otro idioma, aunque tan solo sea por una razón meramente identitaria, como se evidencia en la intervención de la siguiente mujer adulta de El Sol (SG2):

Yo / al menos ya con con A / que es mi única / mi única hija / obviamente yo quiero que ella hable bien el malecu / que lo hable bien / como también yo / desearía que hable bien español y ojalá otro idioma más / porque a la altura de vida que en en la época que estamos / no nos podemos conformar solo con una cosa / obviamente el malecu en primer lugar porque somos indígenas / pero si fuera el caso de que ella / de que yo quisiera que aprendiera más idiomas / por mí / todos los que ella pueda / pero pero el malecu en primer lugar. 


\section{Diferencias de corpus y de expresión entre el malecu y el español}

En relación con las diferencias de corpus ${ }^{11}$ entre el español y el malécu lhaíca, los participantes afirman que no todo lo que se dice en malecu se puede codificar en español o al menos no con la misma "calidad expresiva" (F2, MG1a, MG2, SG1, SG2, SG3a, SG3b, TG1b), y a la inversa: no todo lo que se dice en español se puede expresar en malecu (F1, F2, MG2, MG3a, SG1, SG2, SG3a, TG1b, M2). Incluso se asevera que no existe traducción exacta o equivalencia absoluta para todo entre las dos lenguas (MG2, SG2, M1).

En cuanto a lo que se puede expresar en malecu mejor que en español, sobre todo, salen a relucir manifestaciones discursivas o prácticas lingüísticas que no tienen parangón. Algunas de estas prácticas se suelen plantear de por sí en lingüística como un problema que merece especial atención en lo que respecta a la traducción, como es el caso de los refranes.

Del mismo modo, varios participantes plantean que no existen equivalentes en español para expresar elementos propios de su cultura tradicional: nombres de seres sobrenaturales, linajes, plantas o árboles de la región (SG3a), nombres de animales y antropónimos malecus (TG1b). En el siguiente fragmento, una mujer adulta de El Sol (SG3a) discute sobre el tema de los linajes y seres sobrenaturales con su hermana e insiste en la imposibilidad de encontrar una traducción exacta:

A: $\quad[\ldots]$ hay palabras que no se pueden pronunciar en: español / ¿por qué? / ¿como qué te digo? / no me acuerdo qué era / que una vez estábamos diciendo que cómo se puede decir eso // bueno um: / por ejemplo / una palabra que le dicen Orónhcafi [[un tipo de demonio]] / ese no no hay / es una palabra como / como forma de de sata- / como Satanás / algo así / pero: / no exactamente / entonces no hay una palabra: / que decirle "este es / la palabra" / ¿verdad? / hay palabras que / hay muchas palabras / ¿como qué te digo? este: / este: / \{le habla a su hermana\} B / ¿írri quí ní maráma este máqui corócu lhíja maráma si irrí quenéque? [[¿cómo es que se dicen los otros linajes como el corócu?]]

B: ¿írri? [[¿como qué?]]

A: ofá qui corócu lhíja maráma lhafanhji lhíja maráma [[también los corócu y los lhafanhji]]

B: bueno sí

A: $\quad$ írrima [[¿cómo se puede decir?]]/ eso no se puede decir en chiúti [[español]]

B: $\quad$ ajá / sí lo lo tenemos como grupos de / grupos como como

A: pues sí / pero no hay una palabra como decir "eso significa"

B: $\quad$ ah / no / el significado no

A: $\quad$ sí / es como esas palabras son / grupos / como tribus / sí / entonces este: / hay palabras que en verdad no se pueden / uno no puede.

Por último, se mencionan también como intraducibles -o al menos de traducción poco exitosa- las manifestaciones discursivas de arte verbal (MG2, SG2). Entre ellas, se citan los mayupéca (duelos verbales a los que los participantes suelen referirse como "hablar vulgaridades"), los majuáqui urújeca ('fórmulas de robustecimiento espiritual'), las narraciones (marácunúca) y las plegarias u oraciones (tócu ajá malhaíca). La siguiente discusión entre adultos de El Sol (SG2) resulta muy ilustrativa del enfoque con el que los participantes analizan el problema de traducir al español lo que se suele codificar en malecu. Nótese cómo comentan que en la traducción se pierde "la esencia", "el sentido" o "la gracia" de lo que se expresa en malecu:

A: $\quad[\ldots]$ / como por ejemplo el majuáqui urújeca [[fórmula de robustecimiento espiritual]] y todo eso / ¿cómo se le puede decir en chiúti [[español]]? 
B: $\quad$ sí / es que / digamos / dependiendo del tema ¿verdad? / porque / al menos hay oraciones / en indígena / que que si me lo dicen en español como que no / no coincide ¿verdad? digamos / en lo en lo que están hablando

C: $\quad$ o sea / como que no hay traducción

B: $\quad$ no no no / no se puede traducir ¿verdad? / lo que dicen

A: $\quad$ y se expresa más en malecu que el: / traducirlo en español

C: $\quad$ aunque lo quisieran traducir / quizás muchos lo han hecho / o sea como inventarlo

A: $\quad$ cuesta / cuesta llegarle / como la esencia

C: $\quad$ pueden inventar

A: $\quad$ de lo que se está diciendo en malecu

C: $\quad$ inventar en malecu / pero no

A: $\quad$ sí / porque yo he escuchado eso y nada que ver

B: generalmente digamos / digamos lo que son oraciones \{se refiere a los tócu ajá malhaíca\} / este / cuentos malecu / leyendas \{se refiere a los marácunúca / todo eso / si me lo cuentan en español / para mí no tiene sentido ¿verdad? / [...] / para mí no tiene sentido como como me lo están diciendo / pero si ya un ejemplo / como le digo ¿verdad? / en ese tiempo cuando mis abuelitos existían / ellos se / llegaban / se acostaban / digamos que yo dormía con mi abuelita en ese tiempo / este / ella llegaba / me contaba las historias / todo en malecu ¿verdad?

D: $\quad$ iy de noche de casualidad?

B: $\quad$ y de noche / y yo le entendía muy bien todo lo que ella me decía ¿verdad? / pero si ya me lo traducen / en español /

A: $\quad$ pierde la gracia

B: $\quad$ como que pierde totalmente el sentido de lo que se estaba hablando / digamos / en el / en el dialecto de nosotros / en malecu

C: $\quad$ igual cuando empiezan a contar chistes / chistes y cosas así / vieras que no no

I: $\quad$ chistes en malecu

A: ajá

C: $\quad$ sí / pero muy muy chi- / muy vacilones y vieras que ya / traducirlo en malecu

A: $\quad$ no tiene gracia

C: $\quad$ eh / en español

A: $\quad$ pierde la gracia

C: $\quad$ o sea no

A: $\quad$ o sea yo me destorni- / es más / vea / el papá de este muchacho \{se refiere a uno de los participantes\} con otro señor de Tonjibe bromean y bromean bien pesado \{se infiere que la mujer se refiere a los duelos verbales (mayupéca) $\}$ / pero en malecu / yo me ataco / y como digo me destornillo de la risa / pero ya / en una ocasión un chiúti me pregunta "¿de qué están hablando?" / "es que si te lo traduzco no tiene gracia"

D: no

A: "porque la gracia es malecu" / ya al traducirlo al español pierde la gracia totalmente.

Lo que está de por medio en esta discusión, es la creencia de que existen prácticas de la cultura lingüística tradicional malecu sin equivalencia en la cultura de los chiúti y, por lo tanto, intraducibles al español. Esto es, existe algo así como una cultura lingüística autóctona y, como tal, no puede expresarse por medio de otro código idiomático que no sea el vernáculo sin perder sus rasgos particulares y, en última instancia, el sentido.

En lo que respecta a lo que se dice en español, pero que resulta difícil o imposible de expresar en malecu, se mencionan únicamente, aunque con mucha frecuencia, palabras referidas a objetos de la vida moderna (F2, MG2, MG3a, SG1, SG2, SG3a, TG1b), como 
‘carro' y 'avión'; palabras que designan accidentes geográficos para los que la lengua vernácula carece de denominación, como ‘volcán' (MG2, SG2); y los números mayores al cinco (F1, F2, MG2, SG2, TG1b, M2). Valga destacar, eso sí, que los participantes no parecen concebir estas últimas diferencias de corpus como una limitación en el mismo sentido en que afirman que en español no se puede expresar bien todo lo que se puede decir en malecu. En otras palabras, no se declara que estas lagunas léxicas del malecu constituyan una limitante para el empleo de esta lengua en la vida moderna.

\section{Razones para conservar o aprender malecu y para aprender español}

Desde la perspectiva de los participantes, las razones para conservar o aprender el malécu lhaíca son múltiples y, en general, representan las preocupaciones de la etnia con respecto tanto a su proceso de aculturación como a las necesidades económicas de sobrevivencia. Por un lado, se alude a una motivación utilitaria o instrumental, consistente en atraer al turismo y satisfacer sus expectativas (F1, F2, MG2, MG3a, TG1a), prepararse para futuros trabajos y proyectos de formación educativa en los que se presupone que se solicitará ser malecuhablante (F2, MG3a, TG1a, TG1b), poder realizar las labores escolares de la clase de malecu (F2, MG2, TN) y facilitarse el aprendizaje de otros idiomas (MG1b, MG3a).

Por otro lado, se aduce una motivación integrativa, la cual se manifiesta en el deseo de comprender las historias de los ancianos y participar en las conversaciones entre malecuhablantes (F2, MG1a, MG1b, SG1, SG2, SG3a, SG3b, TG3b). A medio camino entre la motivación instrumental y la identitaria se alude a la posibilidad de recurrir al malécu lhaíca como código críptico intraétnico (F2, MG1b, MG2, SG3a, TG1a). Finalmente, se enfatiza una motivación identitaria, relacionada con el mantenimiento de la cultura y de la lengua ancestrales (MG1b, SG1, SG2, SG3a, TG1a, TG1b, TG2, TG3a), la posibilidad de transmitirles la lengua a las generaciones venideras (MG1a, MG1b, SG1, TG1a, TG1b), la manifestación del orgullo por el origen étnico (MG1c, MG2, TG1b), la necesidad de identificarse y probar que se es malecu (MG1c, MG2, SG1, SG2, SG3a, TG1b, TG3a, TN) y el deseo de dar a conocer al mundo que todavía existen los malecus (TG1b).

La motivación instrumental o utilitaria se plasma por excelencia en el negocio del turismo, una de las fuentes de divisas más importante para Costa Rica y actividad en la que en los últimos años los malecus han incursionado como una forma de asegurarse ingresos que les permitan subsistir y sobreponerse de sus penurias económicas. Al respecto, si bien algunos participantes destacan los problemas que conlleva la mercantilización de su cultura y hasta censuran que se tergiverse la tradición con el fin de aumentar el exotismo y agradar más a los turistas, no niegan que la llegada de estos les permite vender artesanías y ofrecerles "paquetes de inmersión cultural" (caminatas en el bosque con explicación de los usos tradicionales de las plantas, consumición de alimentos preparados a la antigua usanza, visitas guiadas a supuestos sitios de interés cultural, escenificación teatral de antiguas costumbres, etc.), a cambio de sumas de dinero que les permiten a algunos complementar sus magros ingresos y a otros vivir con alguna comodidad. En todo caso, se enfatiza que, como parte del "exotismo" indígena que demanda el turista, hablar la lengua vernácula resulta necesario para poder decirles y enseñarles algunas palabras o frases, o para actuar en una representación teatral.

En lo concerniente a la función integradora, esta aparece principalmente relacionada con el deseo o la necesidad de participar activamente en conversaciones llevadas a cabo en 
malecu, comprender lo que dicen los adultos y entender las narraciones de los ancianos. En el discurso de los adultos, este motivo se emplea para indicarles a los jóvenes que deben aprender la lengua vernácula con el fin de ser capaces de comprender los insultos y, en general, lo que un malecuhablante les diga (SG3a, SG3b, TG3b), como lo explica la siguiente mujer de El Sol (SG3b):

\footnotetext{
[...] yo le enseño a ellos \{a sus hijos\} / "mirá hijos" le digo / "es importante" le digo / "ese esa ese idioma ya se está perdiendo" / le digo / "tal vez alguna persona te dice malas palabras y lo que hacés es reírte nada más" le digo / "no estás oyendo / no estás sabiendo qué es lo que te están diciendo" le digo
}

Por su parte, en el discurso de los jóvenes, el meollo de la motivación se encuentra en su deseo de entablar conversaciones con los adultos y ser capaces de entender y apreciar las historias narradas en malecu por los abuelos (MG1a, MG1b, SG1, SG2), en parte para que estos no se enojen por la falta de competencia de los nietos en la lengua vernácula y en parte porque sienten que se pierden de la riqueza que representaría poder interactuar con sus abuelos en la lengua que estos dominan mejor.

Con rasgos de motivación utilitaria e identitaria al mismo tiempo, se suele resaltar la función críptica del malécu lhaíca como código que les permite a los malecus comunicarse entre sí cuando no quieren ser comprendidos por los chiúti. Esta razón para aprender y conservar el malecu se encuentra en el discurso de todos los grupos generacionales. En el caso de los adultos, estos recurren a enfatizar esta función cuando tratan de hacer que los jóvenes y niños comprendan la importancia de aprender el idioma vernáculo, como lo relata la siguiente anciana de Margarita (F2) a propósito de su malestar con respecto a la falta de competencia de sus nietos en malécu lhaíca.

En el fondo, la anciana apela a la conveniencia de seguir contando con un recurso que permita mantener las fronteras étnicas por medio de una barrera lingüística. El español no sirve para este propósito, ya que todos lo entienden ("todos me escuchan"). En su ejemplo, precisamente trata de mostrar que el malecu le serviría para advertirles a sus nietos sobre la llegada de unos chiúti, de quienes se desconfía ("marrá orróqui tiní itocá maráma" "yo no sé para qué vienen'):

[...] no me entiende qué es \{se refiere a sus nietos\} / qué es lo que le estoy diciendo / sí sí algunas palabritas / saben / pero a veces yo me enojo con ellas / le digo / "qué barbaridad / a veces viene gente blanca" / le digo / ¿qué te puedo decir? / este / "viene / A / ahí viene / B / ahí viene" / yo no sé quién viene ahí / le digo "yo te puedo decir en malecu / este / pa itonh chiúti maráma / marrá orróqui tiní itocá maráma" [[ya vienen los chiúti, yo no sé para qué vienen]] / 'que yo no sé para qué vienen' ¿ve? / así en malecu / pero en chiúti [[español]] / que todos me escuchan / sí \{risas\}

I: $\quad$ para que los chiúti no entiendan

H: $\quad$ ajá / exactamente \{risas\}.

Con respecto a esta motivación, el siguiente relato de una mujer de Margarita (MG2) resulta aleccionador en relación con cómo se valoran en el presente las desventajas de que la lengua vernácula esté perdiéndose, pues con su desaparición se priva a las nuevas generaciones de un instrumento de comunicación intraétnica y críptica, que incluso puede ser de inmensa utilidad en ciertos momentos de peligro, como el relatado por ella, cuando se vio en la necesidad de indicarle a su hijo que corriera para escapar de unos presuntos maleantes sin que estos se percataran de que ella había adivinado sus intenciones:

A: $\quad$ [...] una una vez me sucedió a mí un caso de ¿verdad? / con un chiquito mío / bueno ya ahora es un muchacho / estaba más pequeñito (XX) / sí / como así / me voy yo a la clínica ¿verdad? 


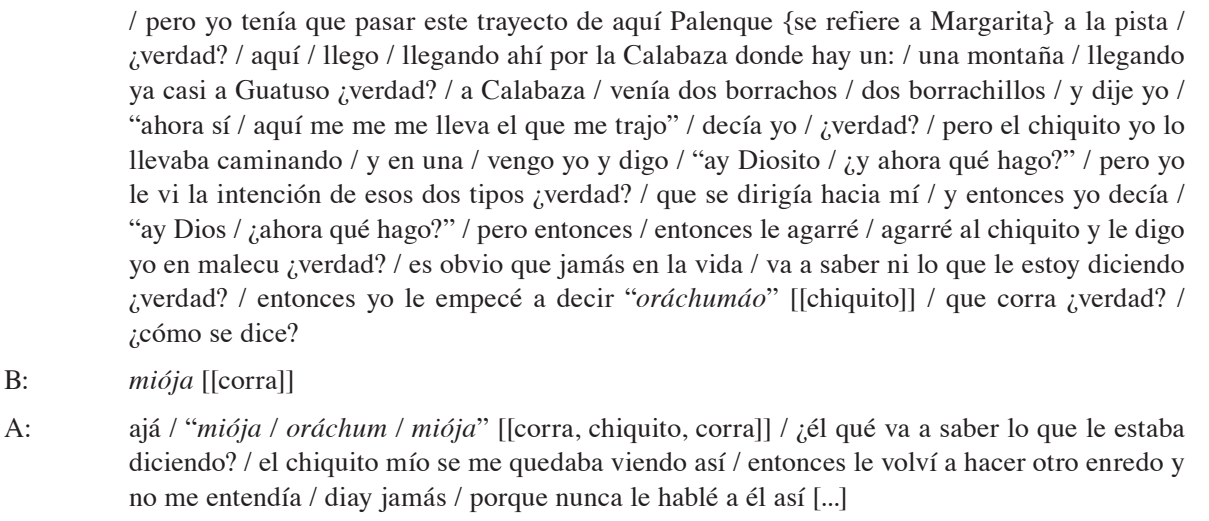

Ya en el ámbito de la motivación identitaria, los participantes defienden la importancia y la necesidad de mantener el malecu y de que las nuevas generaciones lo aprendan aduciendo que deben hablarlo por ser malecus o para manifestar el orgullo de serlo, para identificarse como malecus ante los chiúti y en los encuentros interculturales indígenas, y porque otros grupos indígenas del país sí mantienen sus lenguas vernáculas, de modo que sería reprochable que ellos no. Esta motivación, como puede apreciarse, es compleja y comprende varios aspectos que coinciden, eso sí, en enfatizar la relación entre identidad étnica y lenguaje. En este mismo ámbito, se ubican los razonamientos que apuntan a que el principal motivo para tratar de conservar y rescatar la lengua vernácula consiste en no perder la cultura y continuar con la tradición ancestral.

Esta motivación se halla omnipresente en el discurso de los participantes de los tres palenques y todos los grupos generacionales. Así, por ejemplo, los jóvenes señalan la utilidad de conservar el malécu lhaíca para esclarecer el origen de los malecus ("tenemos raíz indígena" y "que sepa de dónde venimos", afirma una participante de SG1), para diferenciarse de otros pueblos indocostarricenses ("es interesante que esto no se pierda / porque / en todas partes hay indígenas / y todos con su lenguaje / y nosotros / que se vaya a desaparecer eso / nunca Dios lo permita", acota un participante de SG1), para mostrar que se es malecu ante los demás ("la lengua materna de nosotros es lo que nos caracteriza a ser el malecu", afirma una participante de TG1a).

La motivación identitaria se expresa con total explicitud en el siguiente fragmento de la discusión de los adultos de El Sol (SG2). En él, se puede apreciar una amalgama de los argumentos más fuertemente ligados a esta motivación: el malécu lhaíca identifica a los malecus como tales ("es como la identidad de nosotros", "es nuestra esencia"), los diferencia de otros grupos ("es algo que nos distingue en cualquier parte") y, por ende, sirve para demostrar el estatus de malecu ante los chiúti, casi como si constituyera la prueba fehaciente sin la cual no se puede probar la "malequidad", así que no hablarlo implica de por sí un motivo de vergüenza ante el Otro. Nótese cómo la dimensión colectiva ("la identidad de nosotros", "nos distingue", "nuestra esencia") se realza en el discurso cuando los participantes se refieren a la función identitaria que cumple el idioma autóctono:

I: $\quad[. .$.$] ¿por qué sería importante que no se pierda el malécu lhaíca?$

A: $\quad$ yo digo que esa es como la identidad de nosotros / [...] / la identidad de nosotros ¿verdad? / es algo que nos distingue en cualquier parte ¿verdad?

B: es nuestra esencia 
A: $\quad$ pienso yo ¿verdad? porque porque / diay mucha gente a mí me pregunta "¿usted es indígena?"
/ "sí" / y yo he escuchado digamos tal vez con con personas de mi misma edad / "¿usted es
indígena?" / "sí" / "¿pero hablás el malecu?" / "no" / "ah entonces usted no es indígena"
C: $\quad$ para mí sería una vergüenza.

Según lo reportan algunos participantes de Margarita y El Sol (F1, SG1, SG3a), los tonjibeños afirman ser los verdaderos malecus por conservar mejor las tradiciones $y$, principalmente, por hablar más el malécu lhaíca. Esta representación aparece de modo implícito en el discurso de algunos de los participantes de Tonjibe (TG1a, TG1b, TG2), aunque se hace patente en los relatos de situaciones de enfrentamiento o rivalidad entre individuos de Tonjibe y de Margarita, cuando los tonjibeños recurren a su mayor competencia en la lengua vernácula para demostrar su mayor legitimidad étnica. El siguiente extracto de un testimonio de una joven de Tonjibe (TG1b) es claro al respecto:

\begin{abstract}
[...] yo cuando estuve en cuarto año del cole / aquí de noche / vi / había un muchacho que: / él estaba en tercer año / él viaja- / eh: él vive allá en Margarita / y entonces yo vine y y fui al aula donde estaba él / estábamos en tiempo de receso / entonces vengo yo y le digo / “cómo está?” ¿verdad? en malecu / y me contestó "bien" / entonces ya le digo que este: / solo en malecu le hablé ¿verdad? / pero yo le estaba hablando de de la muchacha ¿verdad? / de la profesora / de que si era la turrúcu [[novia]] ¿verdad? / entonces me dice / y yo le hablé todo en malecu / y me dice / le digo "¿me escuchaste?” / "no" me dice / "porque yo ni sé qué es lo que me estás hablando" / le digo "¿pero cómo? / ¿usted es malecu?" / "sí" me dice / "mentira" le digo yo / "usted no es malecu / yo sí te puedo decir que yo soy malecu porque yo sé hablar / y usted no sabe" le digo / "porque usted ni sabe qué es lo que te estoy diciendo" [...]
\end{abstract}

Si bien en algunos grupos y entrevistas se reconoció explícitamente que hablar malecu se considera una parte fundamental de la identidad malecu (F1, F2, MG1a, SG3b, TG1a), en esta representación de la malequidad no se privilegia tanto el "ser" malecu (y, por añadidura, el comportarse como malecu, conocer sobre la cultura malecu y sentirse malecu), sino principalmente el poder "ostentar" una identidad de malecu ante el Otro, que puede ser un chiúti o un indígena costarricense de otra etnia. A este respecto, aparece con especial importancia el conocimiento del malécu lhaíca como símbolo de pertenencia a la categoría y súmmum de lo que significa ser malecu: distinguirse de Otros. Aquí el malécu lhaíca cumpliría, entonces, el papel de servir para la "identidad ostensible", consistente en mostrarse con una identidad étnica diferenciada (MG1a, MG2, SG1, SG2, SG3a, TG1a, TG2). Los siguientes jóvenes de Margarita (MG1a) expresan esta representación con claridad:

I: $\quad[\ldots]$ ¿ustedes piensan que para ser malecu / hay que saber hablar / la lengua malecu / o eso / no tiene nada que ver?

A: no diay / yo diría / diay yo diría que sí tiene algo que ver / porque o sea / ¿de qué vale ser / decir uno "yo soy malecu” si no sabe hablar ni tan siquiera ni una palabra? ¿verdad?

B: $\quad$ por ejemplo / bueno / nosotros salimos mucho / para afuera / decimos / ¿de qué vale decir / "mirá yo soy / yo soy indio" / si yo no sé decir una palabra / si me van a preguntar / “¿cómo se dice tal cosa?" / y no saber contestar es como no ser / no ser indígena.

Como estrategia argumentativa, varios participantes se refieren en sus intervenciones a otros pueblos indocostarricenses (MG1a, MG1c, MG2, MG3a, SG1, SG2, TG1a, TG1b, TG2), lo cual les permite intentar predecir cuál es el futuro del malécu lhaíca si no se hace algo para modificar la situación actual de desplazamiento, en alusión a etnias que ya han perdido su lengua vernácula (MG1a, MG3a, SG1, SG2, TG2), o señalar la falta de lealtad etnolingüística de sus congéneres con respecto a la que ostentan otros grupos cuyo idioma ancestral muestra una fuerte vitalidad (MGla, MG3a, TG1a, TG1b). Así, se alude a los huetares, chorotegas, borucas 
y térrabas como ejemplos de pueblos que ya han perdido sus lenguas y culturas tradicionales en general, frente a los cabécares, bribris y guaymíes, que son idealizados como grupos con una menor aculturación que los malecus y, principalmente, con mayor conservación y uso de sus idiomas ancestrales.

En la siguiente intervención, una joven de El Sol (SG2) enfatiza el valor identificador de hablar malecu como evidencia de que se es indígena y refuerza su tesis con el relato acerca de su experiencia con una anciana boruca en San José, quien le describió la situación de desplazamiento total de la lengua vernácula de su pueblo:

\begin{abstract}
Y y y entonces digo yo "qué importante para todo el malecu" / no solo para / saberlo hablar / sino para identificarse y para que la gente compruebe que de verdad uno / sabe hablar malecu porque / diay de nada vale decir "yo sé / yo soy indígena / pero no entiendo nada en malecu" / y yo digo que preocupante como / bueno voy a poner el caso de / creo que son los borucas / si no me equivoco / yo conoz- eh fui a una feria en San José / conversé con una señora de allá / ya bastante / ya es una adulta mayor / y me dice "yo soy indígena boruca" algo así que me dijo / "¿ajá?" y a mí me llamó la atención / "hábleme en: su idioma" / "no" me dice / "nosotros no tenemos dialecto" / "¿qué?" / o sea yo me asusté / "ipero por qué? / ¿ni los más viejitos?" / "nadie" dice / "nadie conserva la lengua" / o sea ya eso se perdió / si no me equivoco son los borucas / diay yo me quedé así / entonces yo me pongo a pensar qué feo sería el día de mañana que yo diga "soy malecu pero no sé hablar español eh: malecu / nadie habla malecu" [...]
\end{abstract}

Por último, cabe destacar que, para cumplir con la función identificadora, no es importante el "hacer" (usar el malécu lhaíca de modo comunicativamente competente), sino tan solo el "saber" (mostrar que se manejan algunos rudimentos del idioma, sobre todo del componente léxico y del arte verbal). Dicho de otra manera, según se desprende de lo comentado en varios grupos (F2, SG1, SG2, TG1b) y según lo que pudimos corroborar por observación directa in situ, para efectos de la identidad ostensible, se satisface el criterio de hablar malecu con conocer algunas fórmulas de salutación y despedida, cláusulas simples para decir el nombre, términos para denominar a algunos animales y plantas, así como formas tradicionales de vestimenta, comida y cocción de los alimentos.

La representación de que hablar la lengua consiste en conocer unos pocos vocablos y frases aprendidas de memoria se fundamenta en dos hechos comunicativos. En primer lugar, en ningún momento en la actualidad, no manejar de modo competente el idioma malecu constituye un escollo para la comunicación intraétnica, ni siquiera con las personas más ancianas. En segundo lugar, si se trata de evidenciar que se es malecu ante un chiúti o un indígena de otra etnia, basta con poder pronunciar uno que otro enunciado suelto o conocer la traducción de algunas pocas palabras o expresiones.

Por su parte, al español solo se le asigna una motivación instrumental, la cual se manifiesta en varios argumentos: su aprendizaje y empleo sirve para comunicarse con los chiúti (F1, MG1a, SG3a, TG1a, TG1b), para tener acceso a información (F1, F2), para poder comprender lo que se enseña en la escuela y en el colegio sin que medien problemas idiomáticos (MG1c, SG1, SG2, SG3a, TG2) e incluso para poder entender y poder pedir ayuda en caso de que alguien tenga malas intenciones y hable en español (SG2). Es decir, todos los argumentos están centrados en la relación con los que no son malecus o en la necesidad de poder desenvolverse con soltura en las instituciones que se fundaron con la llegada de los chiúti a la región, así como con la incorporación de los malecus al sistema político-económico nacional.

Este reconocimiento de que el español sirve para "estar en el mundo" y tener acceso a lo que sucede "afuera" lo expresa claramente el siguiente adulto mayor de Margarita (F1) mediante una pregunta retórica y la respectiva respuesta, las cuales remiten al aislamiento 
que representaría para los malecus ("nosotros", "solo indígenas”) hablar únicamente la lengua vernácula:

[...] ¿qué haríamos nosotros eh / si no entendemos el español y vivimos solo indígenas? / nunca tuviéramos eh eh / comunicación eh / nunca nos daríamos cuenta / qué es lo que / adónde estamos / cómo estamos.

Debe enfatizarse que el hecho de que todos los argumentos confluyan en la motivación instrumental muestra con claridad la función de la ideología en la representación del lugar que ocupa un idioma dentro de una sociedad. Así pues, a pesar de que el malecu se emplea cada vez menos en la comunicación intraétnica y de que el español ha "acaparado" prácticamente todos los dominios funcionales, se sigue ligando este último idioma con lo foráneo, lo que en origen no es malecu, de forma tal que ni siquiera los participantes sin competencia activa en malécu lhaíca o los ya totalmente monolingües en español mencionan el valor comunicativo del español en su interacción cotidiana con las personas de su misma etnia y en sus familias.

En otras palabras, el vínculo entre lengua malecu e identidad étnica malecu incluso puede llevar a los participantes a no tomar conciencia de que el español constituye en la actualidad el único código dentro del repertorio lingüístico de muchos malecus. Por eso, en sus reflexiones sobre la situación lingüística ideal, los participantes proponen la vía del bilingüismo, incluso con una especie de diglosia motivada por el origen étnico del interlocutor: el malécu lhaíca sirve para hablarles a los malecus, pero a los chiúti hay que hablarles en español, como lo deja en claro el siguiente joven de Tonjibe (TG1b):

[...] a la hora de estar / bueno como estamos aquí en grupo / y ocupo hablar en malecu / tengo que: sentirme bien con mi idioma / estar hablando aquí / pero como decía antes la compañera / es algo lógico / si va a estar con los chiúti / entonces tengo que hablar en español / porque no le voy a hablar en malecu para que ellos se queden bateados / entonces me siento bien / cómodo en los dos / porque así los puedo utilizar los dos / ya estando con diferentes grupos ¿verdad?

Apréciese, cómo el hablante declara que resulta "lógico" pensar que a los chiúti hay que hablarles en español, con lo cual pone en evidencia una proposición ideológica subyacente a su argumentación en lo relativo al papel o estatus de las lenguas: el malécu lhaíca es un código exclusivamente intraétnico, mientras que el español es el código comunicativo escogido por defecto en todas las demás circunstancias. En ningún momento se plantea la posibilidad de que sean los chiúti quienes deban aprender malécu lhaíca, lo que muestra el desequilibrio de poderes que está en juego, evidenciado en la consideración de cuál es la lengua "legítima” (Bourdieu 2008) en la comunicación interétnica.

\section{Conclusiones}

Solo el estudio detallado de las manifestaciones discursivas de las ideologías lingüísticas de un pueblo nos puede revelar el complejo entramado que subyace a las representaciones sobre la naturaleza, el origen, el uso, el valor y las funciones de los elementos que componen los repertorios lingüísticos de una comunidad o de un individuo. Así hemos tratado de mostrarlo en el presente trabajo.

La identidad constituye el eje central de las ideologías lingüísticas de los malecus. Las variedades idiomáticas (sean estas el español y el malecu como lenguas distintas o el geísmo, por ejemplo) funcionan como sustento "material" de la diferencia identitaria establecida con respecto al Otro. Este Otro varía en relación con el grupo de adscripción que se toma como base (la generación, el palenque, la etnia) y se asocia con afiliaciones a distintos colectivos. 
Así, en esencia, la identidad etnolingüística malecu se construye en oposición a la identidad etnolingüística hispana (o chiúti), de modo que la necesidad de establecer, conservar y evidenciar las fronteras grupales subyace a la valoración de las principales funciones que cumple el malécu lhaíca (la comunicación críptica endogrupal, la ostentación y demostración del origen étnico diferenciado) en oposición al español, el cual, aunque sirve para la comunicación en general, se sigue concibiendo como la lengua del Otro (el chiúti lhaíca).

Las ideologías lingüísticas en este caso relacionan el español con lo "externo", lo "ajeno" al pueblo malecu, a pesar de que sea el vehículo de comunicación más usual en el presente entre los malecus y el único código de los individuos monolingües. En otras palabras, existe una representación ideológica que establece un nexo simbólico entre lo autóctono y el malécu lhaíca, en oposición a lo alóctono y el chiúti lhaíca, independientemente de la competencia lingüística de los participantes y de cuál sea el idioma que más comúnmente utilicen en su vida cotidiana. Lo mismo ocurre con el geísmo como rasgo lingüístico que, mediante un proceso de "borrado", se emplea para darle sostén a una división ideológica básica dentro de la etnia: la distinción entre las personas de Tonjibe y las de Margarita y El Sol. Asimismo, también se alude al mayor dominio del idioma autóctono y a la mayor pureza o "completud" con que se habla como una manera de evidenciar fronteras generacionales.

\section{Notas}

1. Durante el tiempo que tomó el análisis de los datos presentados en este artículo, el autor contó con una beca de la Agencia Española de Cooperación Internacional para el Desarrollo. Para el trabajo de campo, contó con el apoyo de la Universidad de Costa Rica. Deseo agradecerle al M.L. Henry Angulo Jiménez por corregir la traducción del resumen al inglés y a la M.L. Patricia Guillén Solano por la revisión filológica del texto.

2. Algunos fragmentos de ejemplo constan de más de una intervención, dado que participan dos o más hablantes, incluyendo al moderador. Cuando esto ocurre, cada intervención se introduce con una letra mayúscula de la A a la E y, en el caso del investigador, sus intervenciones se señalan con I. En los ejemplos se sigue la ortografía regular del español y la ortografía práctica del malecu (Constenla 1998). Las claves de transcripción son las siguientes: / (pausa breve o linde entre enunciados), // (pausa prolongada), [ ] (habla simultánea en el interior de una intervención), $<$ [ ] (habla simultánea iniciada al final de la intervención del participante anterior), MAYÚSCULA (énfasis del hablante: mayor volumen de voz, pronunciación marcadamente segmentada), \{\} (comentarios del transcriptor), (XX) (fragmento ininteligible), (( )) (transcripción dudosa), [...] (fragmento de la grabación omitido), - (truncamientos de palabras), : (alargamiento de segmentos fónicos), cursiva (fragmentos en malecu), [[ ] ] (traducción al español de los fragmentos en malecu), "” (fragmento de discurso directo, casi siempre en un relato conversacional), «» (fragmento de discurso directo dentro de otro discurso directo).

3. Esta teoría popular acerca de la adquisición del lenguaje ha sido denominada la "falacia genética": "The genetic fallacy is the assumption that a person's ancestral or heritage language is genetically easier to learn than other languages or even that it is innate and that a person should, therefore, not have to study or expend any effort in order to learn it (Loether 2009: 246).

4. Esto es, la exogamia no era un prerrequisito, sino que dos personas del mismo linaje podían establecer una relación de pareja.

5. Acuño este término en parangón con fenómenos de fusión fonológica en castellano; en particular, el yeísmo.

6. La fusión de / / / y /x/ implica, evidentemente, que la oposición se neutraliza para algunos hablantes y que, por ende, algunos pares mínimos en el sistema fonológico más conservador (como púlhi /pu:łi/ 'pizote' frente a púji /pu:xi/ 'abeja mariola pequeña') se conviertan en palabras homófonas. Véase Constenla (1998).

7. Se representa la lateral fricativa sorda con el dígrafo «lh» en la ortografía práctica del malecu, mientras que la fricativa velar se representa con «j». No obstante, si bien el geísmo aparece en todos los hablantes, 
únicamente lo hemos representado con «j» en la transcripción en el caso de los participantes tonjibeños o cuando los hablantes contrastan la pronunciación distinguidora frente a la geísta.

8. En este ejemplo únicamente debe prestársele atención a la distinción relativa a «lh» y «j». La participante cambia el prefijo de persona ( $(\mathrm{a}-\mathrm{o} \mathrm{ma}$-) en varias ocasiones, pero no se trata de que uno sea característico de Tonjibe y otro de El Sol, sino de que la palabra fílhi es de tipo relacional (o de posesión inalienable), de modo que siempre debe aparecer con un prefijo de persona (Constenla 1998). Esto hace que a la hablante no le parezca normal decir fílhi sin algún prefijo, así que unas veces opta por agregar el de primera persona exclusiva $n a$ - y otras el de primera persona inclusiva o de persona indefinida $m a-$. El segundo significado de $m a$ - es el que más probablemente quiso expresar la participante en este caso, como se evidencia en su traducción mafiji 'los ojos'.

9. Nótese, nuevamente, cómo alternan la lateral sorda [1] y la fricativa velar [x] en un mismo hablante en cuestión de segundos (primero pronuncia lhíja y casi inmediatamente después dice jíja). Precisamente este caso ilustra a la perfección la situación de este cambio lingüístico en Margarita y El Sol.

10. Es decir, la vendedora comprendió la petición de la niña debido a los hispanismos ('leche', 'picarita') que esta empleó en su discurso en malecu.

11. Tomamos el término del ámbito de la planificación lingüística, en el que se utiliza para aludir a los recursos formales con que cuenta una lengua: palabras, estructuras morfosintácticas, modalidades discursivas, sistemas de escritura (Fishman 1989).

\section{Bibliografía}

Bader, Gloria E. y Catherine A. Rossi. 2002. Focus Groups. A Step-by-Step Guide. Canadá: The Bader Group.

Barnouw, Erik et al. 1989. International Encyclopedia of Communication. Oxford: Oxford University Press.

Boudreau, Annette y Lise Dubois. 2008. "Français, acadien, acadjonne: Competing discourses on language preservation along the shores of the Baie Sainte-Marie". En: Duchêne y Heller (Eds.). 99-120.

Bourdieu, Pierre. 2008. ¿Qué significa hablar? Economía de los intercambios lingüísticos. Madrid: Akal.

Callejo, Javier. 2001. El grupo de discusión: introducción a una práctica de investigación. Barcelona: Ariel.

Constenla Umaña, Adolfo. 1975. La lengua guatusa: fonología, gramática y léxico. Tesis de licenciatura en Filología española: Universidad de Costa Rica.

1998. Gramática de la lengua guatusa. Heredia: Editorial de la Universidad Nacional.

Constenla Umaña, Adolfo, Eustaquio Castro y Antonio Blanco. 1993. Laca Majifijica. La transformación de la tierra. San José: Editorial de la Universidad de Costa Rica.

Coupland, Nikolas y Adam Jaworski (Eds.). 2009. Sociolinguistics. Londres: Routledge.

Duchêne, Alexandre y Monica Heller (Eds.). 2008. Discourses of Endangerment. Ideology and Interest in the Defense of Languages. Londres: Continuum.

Field, Margaret y Paul Kroskrity. 2009. "Introduction. Revealing Native American Language Ideologies". En: Kroskrity y Field (Eds.). 3-28.

Fishman, Joshua. 1989. Language and Ethnicity in Minority Sociolinguistic Perspective. Clevedon: Multilingual Matters Ltd. 
Fought, Carmen. 2006. Language and Ethnicity. Cambridge: Cambridge University Press.

Galindo Cáceres, Jesús (Coord.). 1998. Técnicas de investigación en sociedad, cultura y comunicación. México: Prentice Hall.

García Segura, Guillermo y Xinia Zúñiga Muñoz. 1987. Acciones educativas para la revitalización lingüística. San José: Ministerio de Educación Pública.

Geeraerts, Dirk. 2008. "The Logic of Language Models: Rationalist and Romantic Ideologies and their Avatars". En: Süselbeck et al. (Eds.). 43-73.

Heath, Shirley Brice. 1989. “Language Ideology”. En: Barnouw et al. (Eds.). 393-395.

Irvine, Judith T. y Susan Gal. 2009. "Language ideology and linguistic differentiation". En: Coupland y Jaworski (Eds.). 249-290.

Kroskrity, Paul V. y Margaret C. Field (Eds.). 2009. Native American Language Ideologies: Beliefs, Practices, and Struggles in Indian Country. Arizona: University of Arizona Press.

Krueger, Richard A. y Mary Anne Casey. 2000. Focus Groups. A practical guide for applied research. Londres: SAGE.

Le Page, R.B. y Andrée Tabouret-Keller. 1985. Acts of identity. Creole-based approaches to language and ethnicity. Cambridge: Cambridge University Press.

Loether, Christopher. 2009. "Language Revitalization and the Manipulation of Language Ideologies: A Shoshoni Case Study”. En: Kroskrity y Field (Eds.). 238-254.

Mejía Marín, Noemy et al. 1995. Historias malecus. Heredia: EUNA.

Morgan, David L. 1997. Focus groups as qualitative research. Londres: SAGE.

Rumsey, Alan. 1990. "Wording, Meaning, and Linguistic Ideology”. American Anthropologist 92 (2): 346-361.

Russi Alzaga, Bernardo. 1998. "Grupos de discusión. De la investigación social a la investigación reflexiva”. En: Galindo (Coord.).: 75-115.

Sánchez Avendaño, Carlos. 2011. El desplazamiento de la lengua guatusa en contacto con el español: Identidad étnica, ideologías lingüísticas y perspectivas de conservación. Tesis doctoral: Universidad Autónoma de Madrid.

Inédito. "Los indios lo que hablan es un dialecto. Representaciones de los hispanos con respecto a los malecus y su lengua vernácula”. Revista de Filología, Lingüística y Literatura.

Schieffelin, Bambi B., Kathryn A. Woolard y Paul V. Kroskrity (Eds.). 1998a. Language Ideologies. Practice and Theory. Oxford: Oxford University Press.

1998b. "Preface". En: Schieffelin et al. (Eds.). 5-7.

Sierra, Francisco. 1998. "Función y sentido de la entrevista cualitativa en investigación social". En: Galindo (Coord.): 277-345.

Süselberck, Kirsten, Ulrike Mühlschlegel y Peter Masson (Eds.). 2008. Lengua, Nación e Identidad. La regulación del bilingüismo en España y América Latina. Madrid: Iberoamericana Vervuert.

Woolard, Kathryn A. 1998. “Introduction. Language Ideology as a Field of Inquiry”. En: Schieffelin et al. (Eds.). 3-47. 
Zimmermann, Klaus. 2001. "Interculturalidad y contacto de lenguas: condiciones de la influencia mutua de las lenguas amerindias con el español". En: Zimmermann y Stolz (Eds.). 17-34.

Zimmermann, Klaus y Thomas Stolz (Eds.). 2001. Lo propio y lo ajeno en las lenguas austronésicas y amerindias. Procesos interculturales en el contacto de lenguas indígenas con el español en el Pacífico e Hispanoamérica. Madrid: Vervuert Iberoamericana. 